\title{
Transient Responses and Appropriate Fault Protection Solutions of Uni-grounded AC Microgrids
}

\author{
Keng-Yu Lien ${ }^{1}$, Duong Minh Bui ${ }^{2}$, Yung-Ruei Chang ${ }^{3}$, Yih-Der Lee ${ }^{3}$, Jheng-Lun Jiang ${ }^{3}$, \\ Ching-Chih Lin² \\ ${ }^{1}$ Department of Avionics, China University of Science and Technology, Hsinchu, Taiwan. \\ 2 Department of Electrical Engineering, Chung Yuan Christian University, Chungli, Taiwan. \\ ${ }^{3}$ Institute of Nuclear Energy Research, Atomic Energy Council, Taoyuan, Taiwan. \\ *Corresponding author. Tel.: +886-978-844-211, email: duong.1041030@yahoo.com \\ Manuscript submitted September 26, 2015; accepted April 11, 2016. \\ doi: 10.17706/ijcee.2016.8.2.132-150
}

\begin{abstract}
This paper simulates transient situations of a uni-grounded low-voltage (LV) AC microgrid through various fault tests and operation transition tests between grid-connected and islanded modes of the uni-grounded microgrid. Based on transient simulation results, available fault protection methods are proposed for main and back-up protection of a uni-grounded AC microgrid. As a result, main contributions of the paper are: (i) analysing transient responses of a uni-grounded LVAC microgrid through line-to-line faults, line-to-ground faults, three-phase fault and microgrid operation transition tests; and (ii) proposing available fault protection methods for uni-grounded microgrids, such as: non-directional or directional overcurrent protection, under/over voltage protection, differential protection, voltage-restrained overcurrent protection, and other protection principles not based on phase currents and voltages (e.g. total harmonic distortion detection of currents and voltages, using sequence components of current and voltage, $3 I_{0}$ or $3 V_{0}$ components).
\end{abstract}

Key words: Fault protection, microgrid transient responses, microgrid simulation, uni-grounded microgrid.

\section{Introduction}

Microgrid (MG) is a small power system containing distributed generators (DGs), energy storage systems (ESSs), and dispersed loads, which can operate at grid-connected and islanded modes in safety, stability and reliability due to protective devices, energy management systems, and control strategies [1], [2]. The microgrid mainly operates at low-voltage and medium-voltage levels to adapt to operating voltage requirements of electrical equipment at households and industrial parks. Distributed generators can be renewable energy sources such as photovoltaic (PV), wind, fuel cell (FC) stack, or can be non-renewable energy sources such as micro/small hydro, micro-turbines, diesel generators. Energy storage systems can be battery packs, super-capacitors, flywheels. DGs and ESSs are mostly connected to a microgrid through power electronic converters, isolation transformers, or both of them. In relation to microgrid operation, using the converters is to control power flows, stabilise microgrid voltage and frequency, eliminate harmonics, and convert AC voltages into DC voltages and vice-versa [3], [4]. Besides that, use of isolation transformers at DG and ESS branches in an AC microgrid is to decay DC components and configure 3-phase \& 5-wire, 3-phase \& 4-wire, 3-phase \& 3-wire, 1-phase \& 2-wire, or 1-phase \& 3-wire AC microgrids.

Based on different grounding diagrams of DGs, ESSs, interface converters, and isolation and distribution 
transformers, microgrids can be classified into ungrounded microgrids, uni-grounded microgrids and multi-grounded microgrids. A uni-grounded microgrid has a unique grounding point at a distribution transformer. The distribution transformer is placed between a microgrid and a distribution grid, which increases the MG voltage to a distribution voltage level. A multi-grounded microgrid structure has many grounded neutral points at isolation transformers, distribution transformers, and distributed energy resources. In order to clearly understand about operation characteristics of uni-grounded microgrids, this paper simulates transient situations of a typical uni-grounded LVAC microgrid through different fault tests (including line-to-line (LL) faults, line-to-ground (LG) faults, and three-phase (TP) fault) and a microgrid operation transition test. Relied on transient simulation results, available fault protection methods are proposed for main and back-up protection of a uni-grounded AC microgrid. The uni-grounded MG's transient simulation results are focused on parameters of phase fault currents and voltages as well as other parameters such as: total harmonic distortion (THD) of phase currents and voltages, positive-negative-zero sequence components of currents and voltages, $3 I_{0}$ and $3 V_{0}$ components, and so on. Available fault protection methods proposed for uni-grounded AC MGs use basic protection principles such as non-directional or directional overcurrent protection, under/over voltage protection, differential protection, and voltage-restrained overcurrent protection or use other protection principles not based on phase currents and voltages.

\section{Transient Simulation Cases of a Typical Uni-Grounded Low-Voltage AC Microgrid}

A typical uni-grounded LVAC microgrid configuration is indicated in Fig. 1. This simulated typical uni-grounded microgrid uses actual parameters of a 380V AC microgrid test-bed built at Institute of Nuclear Energy Research, Taiwan. More clearly, the simulated uni-grounded microgrid has a $20.16 \mathrm{~kW}$ photovoltaic (PV) generation system, a $100 \mathrm{kWh}$ battery power conditioning system (PCS), and a $65 \mathrm{~kW}$ gas micro-turbine (MT) system. Other technical parameters of the simulated microgrid are depicted in Fig. 1. There are six microgrid digital relays (MDR) and one static switch (SS) installed to protect the uni-grounded microgrid. Concretely, MDR1, MDR4 and MDR5 are placed at MT, PV, and PCS branches, respectively. MDR2 is placed at a load branch. MDR6 and MDR7 are used to protect a trunk line containing an isolation transformer TR\#3. The SS is set at a secondary side of a distribution transformer (TR\#1). All neutral points of isolation transformers (TR\#2, TR\#3, TR\#4 \& TR\#5) are grounded through a solely grounded neutral point of a distribution transformer TR\#1. Transient behaviours of a uni-grounded LVAC microgrid are surveyed through single-line to ground (SLG) faults, three-phase (TP) fault, and line-to-line (LL) faults at three different locations (including location of a trunk line $\left(\mathrm{F}_{2}\right)$, location of an $\mathrm{AC}$ common bus $\left(\mathrm{F}_{3-1}\right)$, and output of a DC/AC inverter at the PV branch $\left(\mathrm{F}_{3-2}\right)$ ) and a MG's operation transition test from an islanded mode into a grid-connected mode. It is noted that faults occurring at locations of distributed energy resources (e.g. PV arrays, battery packs, AC generators, etc.), transformers, and inverters in a uni-grounded microgrid are not surveyed because IEEE1547 standard has mentioned typical examples how to protect them against the faults [5]. In addition, different faults occurring at load branches in a uni-grounded MG are also ignored because it is not so complex to select appropriate fault protection solutions for load branches.

In relation to operation of a uni-grounded microgrid simulation model, a PV system, a battery system, and a micro-turbine system operate at an islanded mode from $0 \mathrm{~s}$ to $60 \mathrm{~s}$, and they are connected to the utility grid after the $60^{\text {th }}$ second. Starting time of the micro-turbine system is about 40 s, so it is interconnected to the PV and battery systems from the $45^{\text {th }}$ second. After 60 s, the micro-turbine system will be synchronized to the utility grid along with the PV and battery systems. SLG, LL, and TP faults are assumed to occur at the $10^{\text {th }}, 50^{\text {th }}$ and $62^{\text {nd }}$ seconds in a simulated uni-grounded AC microgrid. An operation transition test of a uni-grounded MG from the islanded mode to the grid-connected mode is simulated at the $60^{\text {th }}$ second. 
Referred to Fig. 1, two digital relays MDR6 and MDR7 are used to detect the faults at $F_{2}$. At a faulted location $\mathrm{F}_{3-1}$, MDR4, MDR5 \& MDR7 are used to protect the common bus. At a location $\mathrm{F}_{3-2}$, MDR4 is used to protect the PV branch. Lastly, the static switch is utilised to isolate a uni-grounded MG from faults at the grid side.

During transient simulations of a uni-grounded 380V AC MG, parameters are observed consisting of fault currents and voltages at each phase $\left(I_{a}, I_{b}, I_{c}, V_{a}, V_{b}\right.$, and $V_{c}$ at phases $a, b$, and $\left.c\right)$, total harmonic distortion (THD) of currents and voltages at each phase $\left(T H D_{I a}, T H D_{I b}, T H D_{I c}, T H D_{V a}, T H D_{V b}\right.$, and $\left.T H D_{V c}\right)$, positive/negative/zero sequence current and voltage components $\left(I_{\text {pos }}, I_{\text {neg }}, I_{\text {zero }}\right.$ and $V_{\text {pos }}, V_{\text {neg }}, V_{\text {zero }}$, respectively), $3 I_{0}$ and $3 V_{0}$ components, and other parameters such as $\left|I_{\text {neg }}\right| /\left|I_{\text {pos }}\right|,\left|I_{\text {zero }}\right| /\left|I_{\text {pos }}\right|$, $\left(\left|I_{\text {neg }}\right|+\left|I_{\text {zero }}\right|\right) /\left|I_{\text {pos }} \downarrow,\right| V_{\text {neg }}|/| V_{\text {pos }}|,| V_{\text {zero }}|/| V_{\text {pos }}\left|,\left(\left|V_{\text {neg }}\right|+\left|V_{\text {zero }}\right|\right) /\right| V_{\text {pos }} \mid$, voltages at a $d$ - $q$ rotating reference frame ( $E_{d}$ and $E_{q}$, respectively), $I_{d}$ parameter $\left(I_{d}=\left|I_{a}\right|+\left|I_{b}\right|+\left|I_{c}\right|\right)$ and $I_{d n}$ parameter $\left(I_{d n}=I_{a}+I_{b}+I_{c}+I_{n}\right)$.

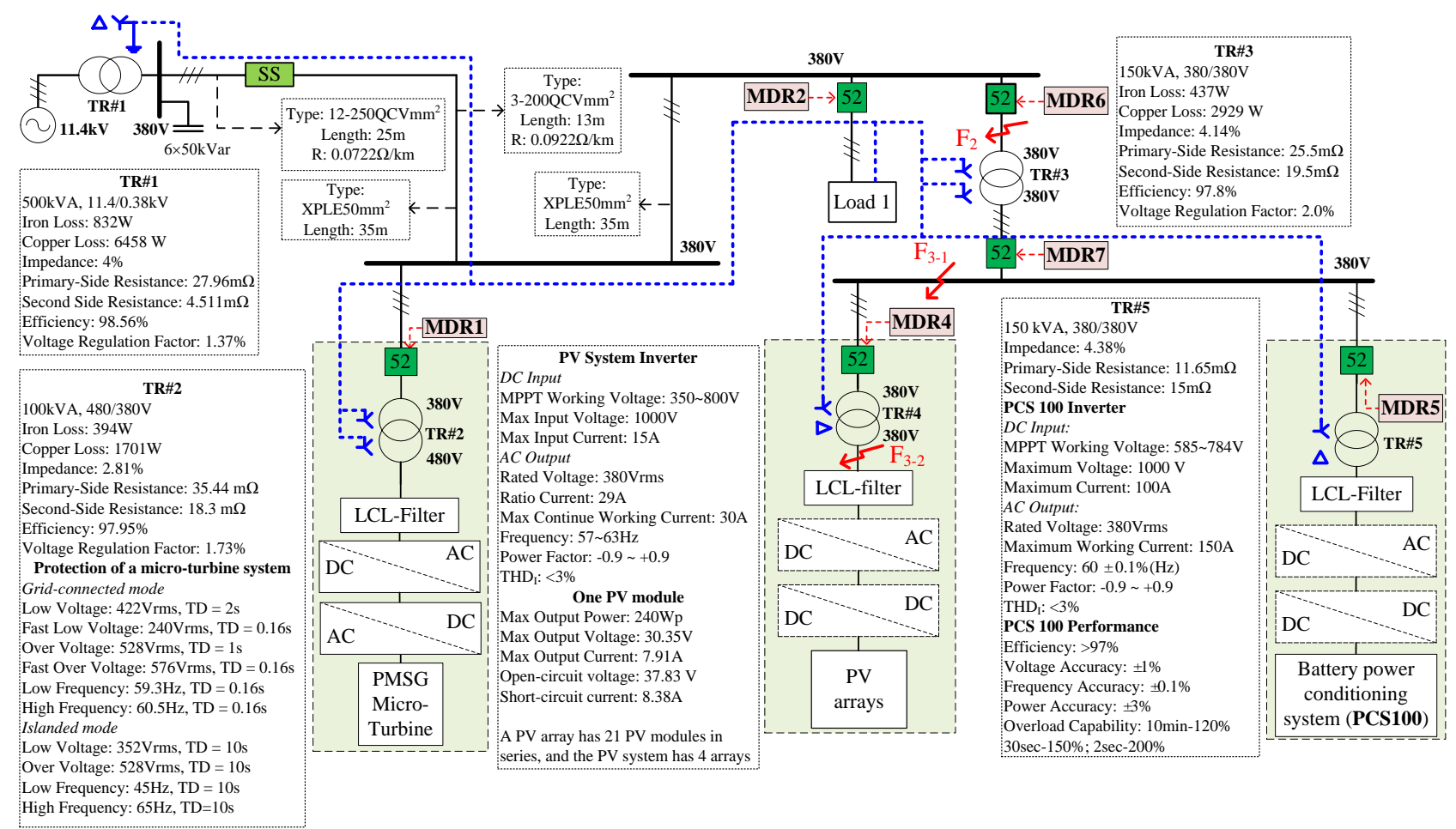

Fig. 1. A typical uni-grounded 380V AC microgrid configuration is simulated by PSCAD software.

\subsection{Faults at an $A C$ Trunk Line $\left(F_{2}\right)$ in a Uni-Grounded $M G$}

Fig. 2, Fig. 3, and Fig. 4 show simulation results of SLG, TP, and LL faults, respectively, from a typical uni-grounded MG. It is noted that the fault time is $0.1 \mathrm{~s}$.

\subsubsection{Faults occurring at the $5^{\text {th }}$ second at location $F_{2}$}

At this time, micro-turbine, PV, and battery power conditioning systems operate at an islanded mode, the battery system is fully charged, and total load power is $18 \mathrm{~kW}$. Referred to Fig. 2, parameters of phase currents and voltages, THD of currents and voltages, $I_{\text {pos }}, I_{\text {neg }}, I_{\text {zero }}, V_{\text {pos }}, V_{\text {neg }}, 3 I_{0}, 3 V_{0},\left|I_{\text {neg }}\right| /\left|I_{\text {pos }}\right|,\left|I_{\text {zero }}\right| /\left|I_{\text {pos }}\right|$, $\left(\left|I_{\text {neg }}\right|+\left|I_{\text {zero }}\right|\right) /\left|I_{\text {pos }}\right|,\left|V_{\text {neg }}\right| /\left|V_{\text {pos }}\right|,\left(\left|V_{\text {neg }}\right|+\left|V_{\text {zero }}\right|\right) /\left|V_{\text {pos }}\right|, E_{d}$, and $I_{d n}$ can be used to detect a single-line to ground fault at $F_{2}$ in a uni-grounded $A C M G$ because their values significantly change from a normal operation mode to a faulted operation mode. On the other hand, in order to identify which phase is faulted in a SLG fault case, THD values, phase current and voltage parameters can be utilised to solve this problem. See Fig. 2, the $T H D_{V a}, T H D_{I a}, V_{a}$, and $I_{a}$ values at phase $a$ are the highest in comparison with those at two remaining phases. The fault current $I_{a}$ is limited to $2.0 \mathrm{pu}$ for each inverter-based DG branch, but the fault current containing a DC-offset component leads to a higher peak fault current value, referred to Fig. 2(j). 


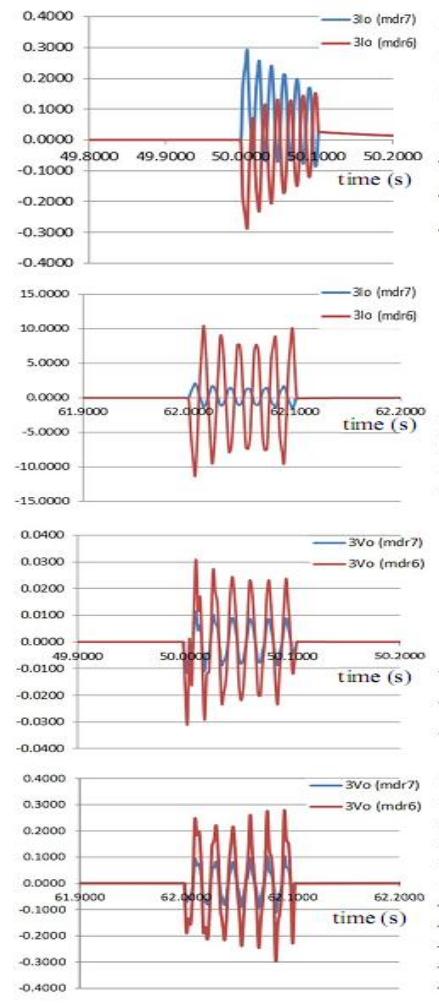

(a) 3Io and $3 \mathrm{Vo}$ components of MDRs 6 \& 7 for a SLG fault at $50^{\text {th }}$ and $62^{\text {nd }}$ seconds.

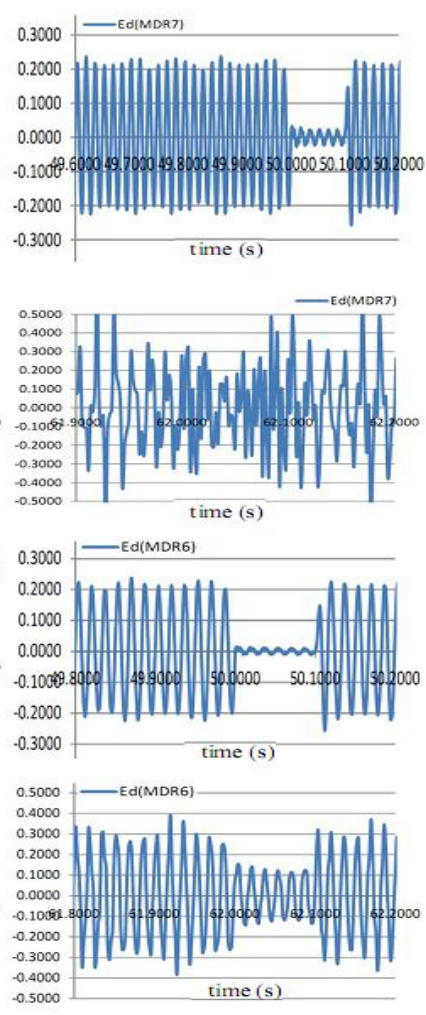

(b) Ed voltage components of MDR7 and MDR6 for a SLG fault at the $50^{\text {th }}$ and $62^{\text {nd }}$ seconds.

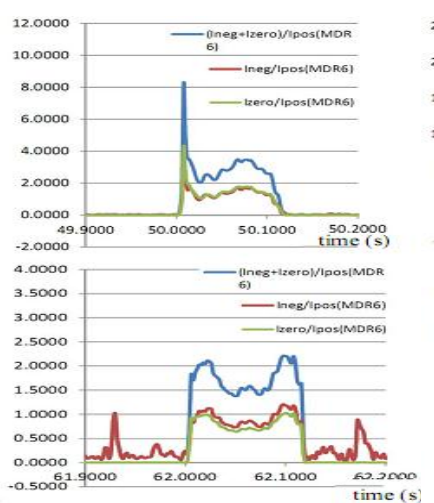

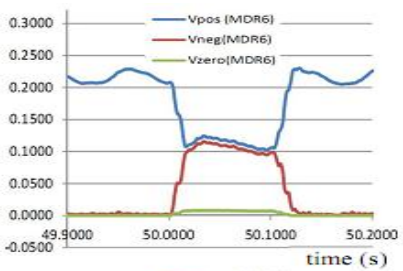
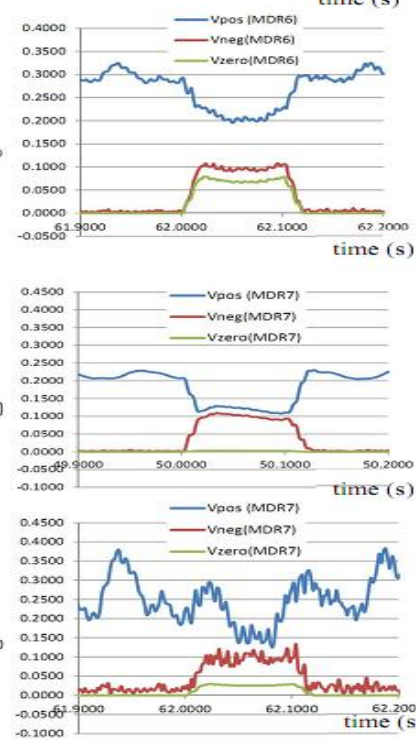

(c) Vpos, Vneg, and Vzero components of MDRs 6 \& 7 for a SLG fault at the $50^{\text {th }}$ and $62^{\text {nd }}$ seconds.
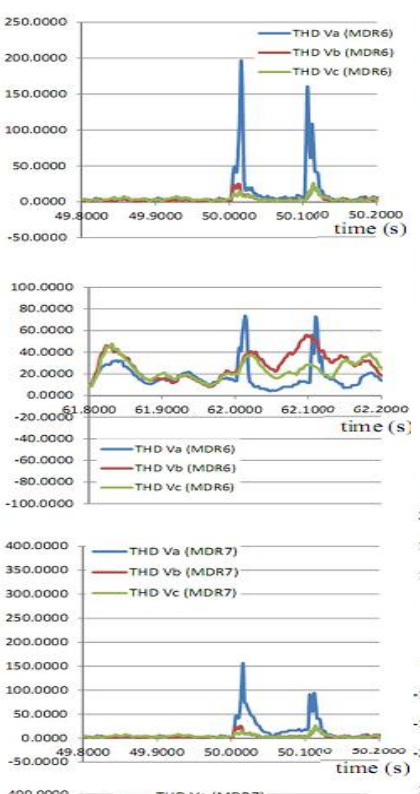

(e) Ipos, Ineg, and Izero components of MDRs $6 \& 7$ for a SLG fault at the 50th and $62 \mathrm{nd}$ seconds. (f) $\quad(\mid$ Ineg $|+|$ Izero $\mid) / \mid$ Ipos $\mid$, |Ineg|/IIpos|, |Izero|/IIpos|, components of MDRs 6 \& 7 for a SLG fault at $50^{\text {th }} \& 62^{\text {nd }}$ seconds. (g) THDVa, THDVb and THDV components of MDR7 and MDR6 for a SLG fault at the $50^{\text {th }}$ and $62^{\text {nd }}$ seconds.
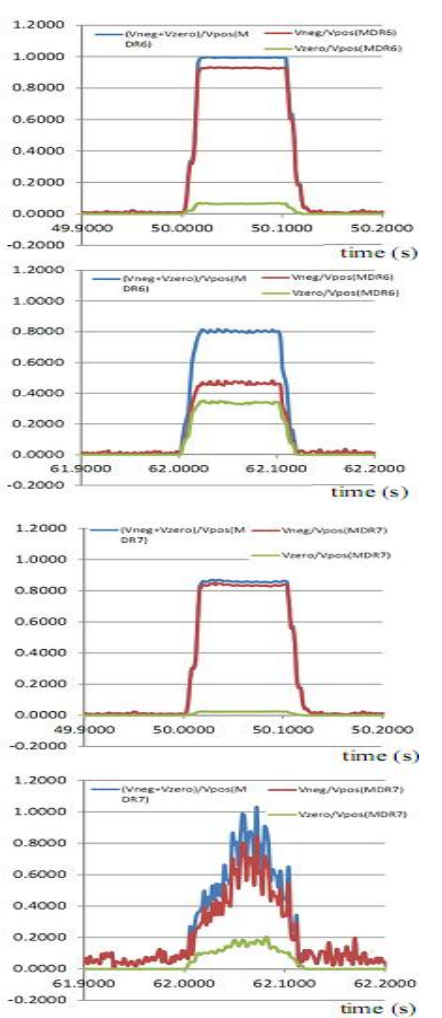

(d) (|Vneg $|+|$ Vzero $\mid) / \mid$ Vpos $\mid$, |Vneg|/|Vpos|, |Vzero|/|Vpos| components of MDRs $6 \& 7$ for a SLG fault at $50^{\text {th }} \& 62^{\text {nd }}$ seconds.

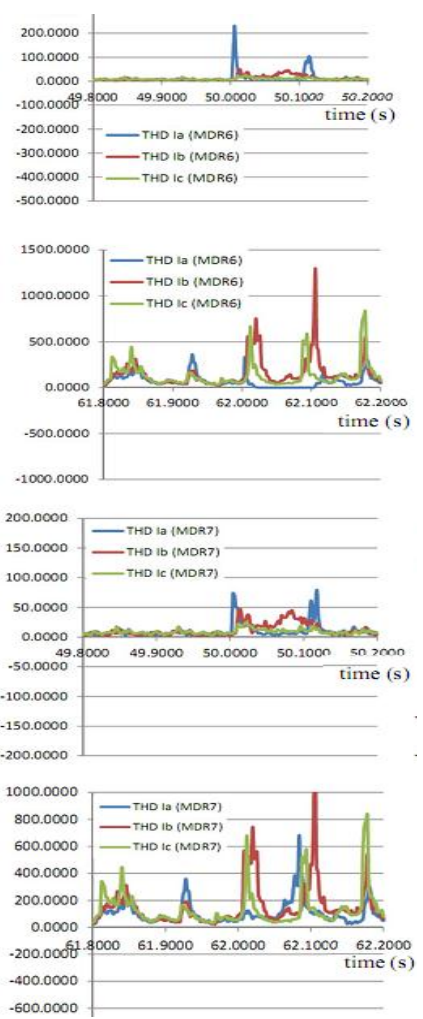

(h) THDIa, THDIb and THDIc components of MDR7 and MDR6 for a SLG fault at the $50^{\text {th }}$ and $62^{\text {nd }}$ seconds. 


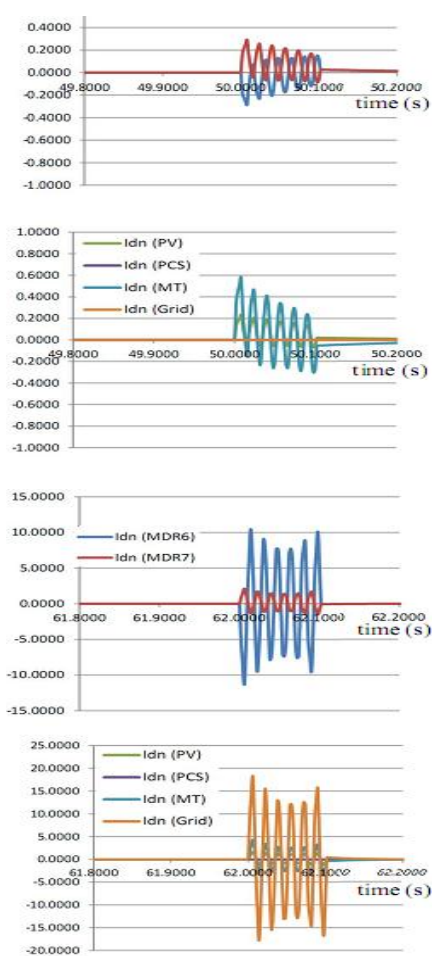

(i) Idn components at MDRs 6 \& 7 for a SLG fault at the 50th and 62nd seconds; Idn (PV), Idn (PCS), Idn (MT), and Idn (Grid).

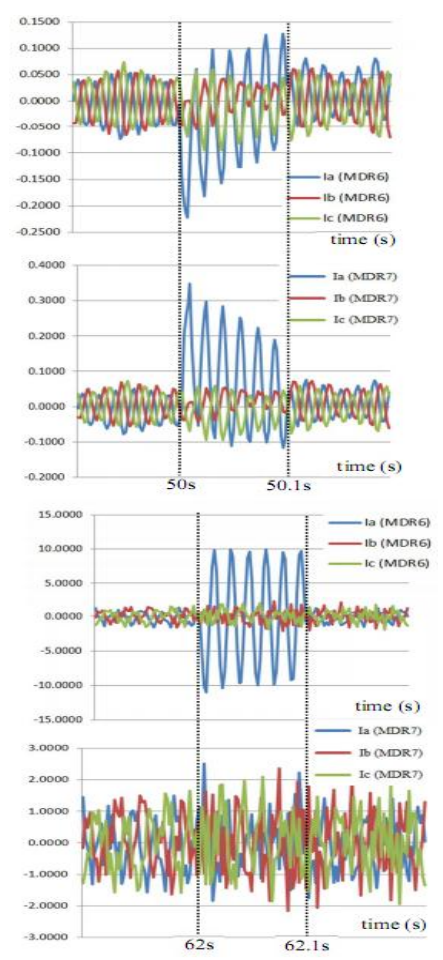

(j) Ia, Ib and Ic components of MDR7 and MDR6 for a SLG fault at the 50th and 62 nd seconds.

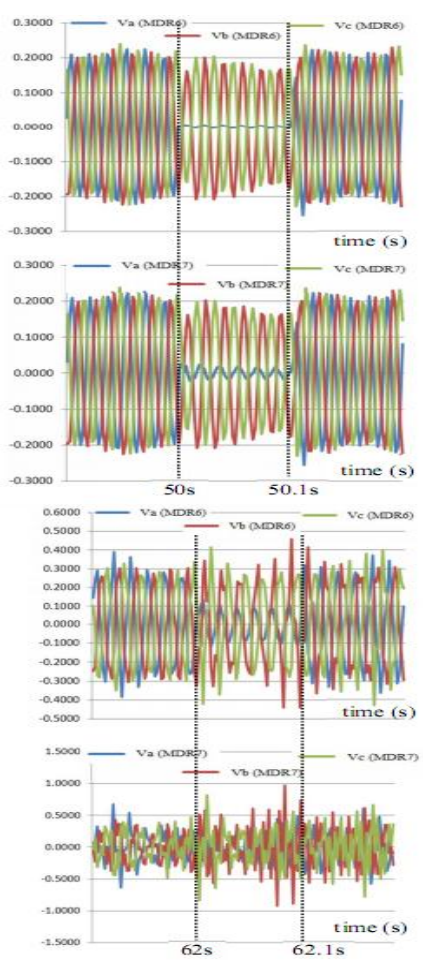

(k) Va, $\mathrm{Vb}$ and $\mathrm{Vc}$ components of MDR7 and MDR6 for a SLG fault at 50th and 62nd seconds.

Fig. 2. Simulation results of a single-line to ground (SLG) fault occurring at the $A C$ trunk line $\left(F_{2}\right)$ of a uni-grounded microgrid.

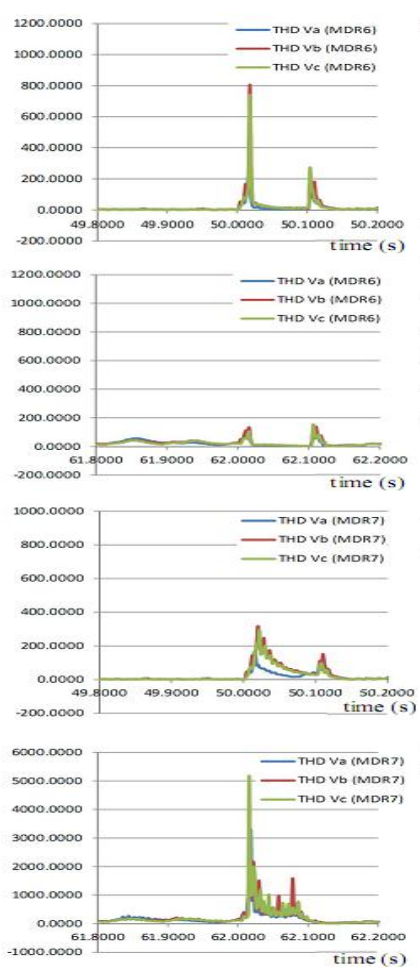

(a) $T H D_{V a}, T H D_{V b}$ and $T H D_{V c}$ components of MDR7 and MDR6 for a TP fault occurring at the $50^{\text {th }}$ and $62^{\text {nd }}$ seconds.

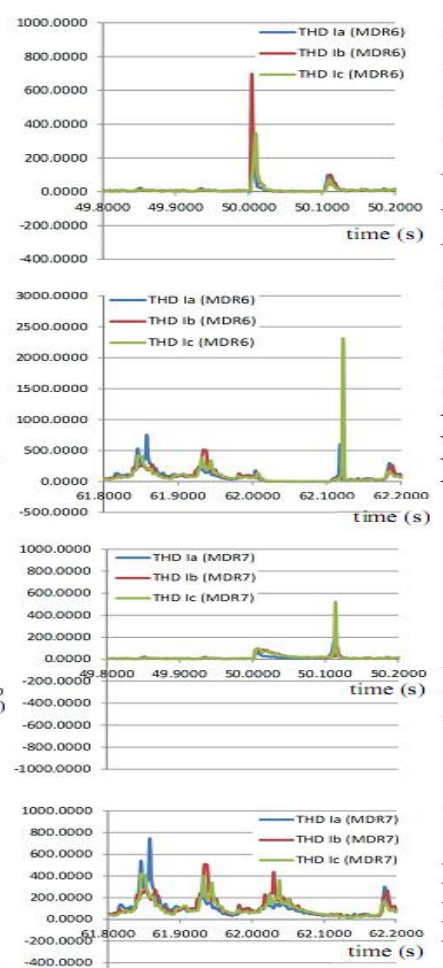

(b) $T H D_{I a}, T H D_{I b}$ and $T H D_{I c}$ components of MDR7 and MDR6 for a TP fault occurring at the $50^{\text {th }}$ and $62^{\text {nd }}$ seconds.

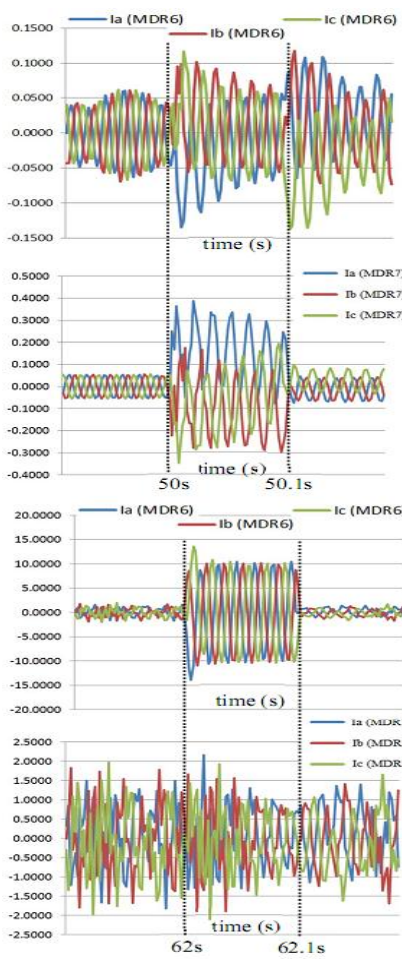

(c) $I_{a}, \quad I_{b}$ and $I_{c}$ current components of MDR7 and MDR6 for a TP fault at the $50^{\text {th }}$ and $62^{\text {nd }}$ seconds.

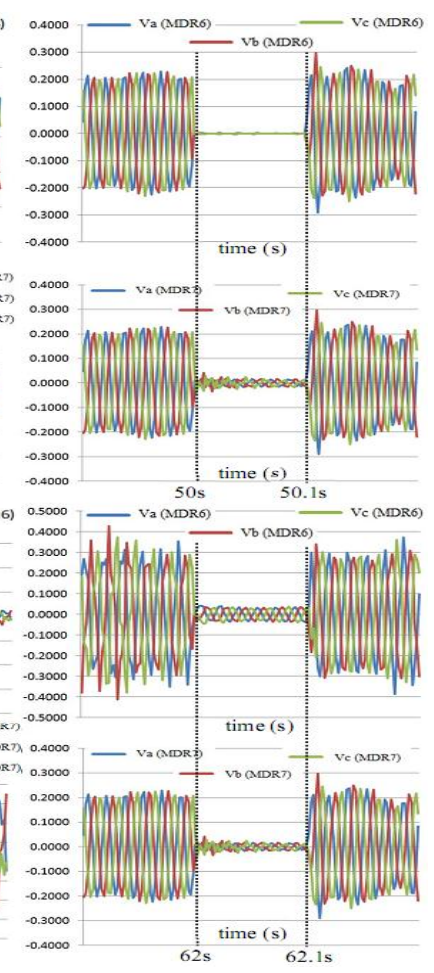

(d) $\quad V_{a}, \quad V_{b}$ and $V_{c}$ voltage components of MDR7 and MDR6 for a TP fault at the $50^{\text {th }}$ and $62^{\text {nd }}$ seconds.

Fig. 3. Simulation results of a three-phase (TP) fault occurring at the AC trunk line (F2) of a uni-grounded microgrid. 


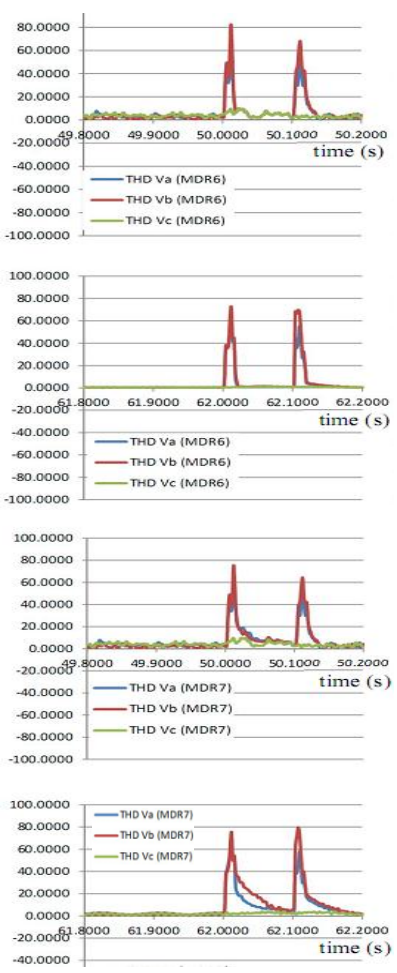

(a) $T H D_{V a}, T H D_{V b}$ and $T H D_{V c}$ components of MDRs $6 \& 7$ for a LL fault occurring at the $50^{\text {th }}$ and $62^{\text {nd }}$ seconds.

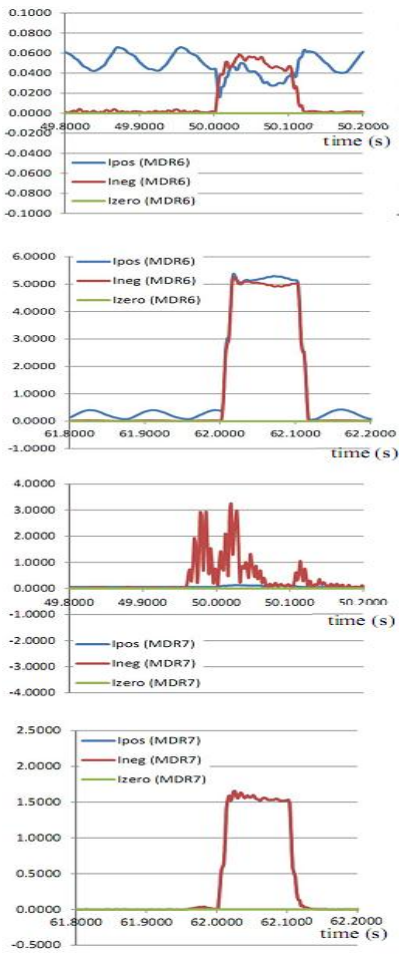

(d) $I_{p o s}, I_{\text {neg }}$, and $I_{\text {zero }}$ current components of MDR7 and MDR6 for a LL fault occurring at the $50^{\text {th }}$ and $62^{\text {nd }}$ seconds

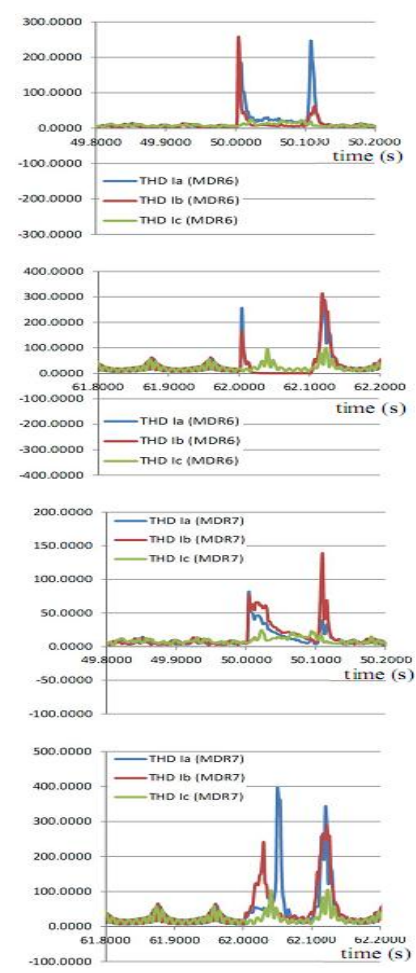

(b) $T H D_{I a}, T H D_{l b}$ and $T H D_{I c}$ components of MDRs $6 \& 7$ for a LL fault occurring at the $50^{\text {th }}$ and $62^{\text {nd }}$ seconds.

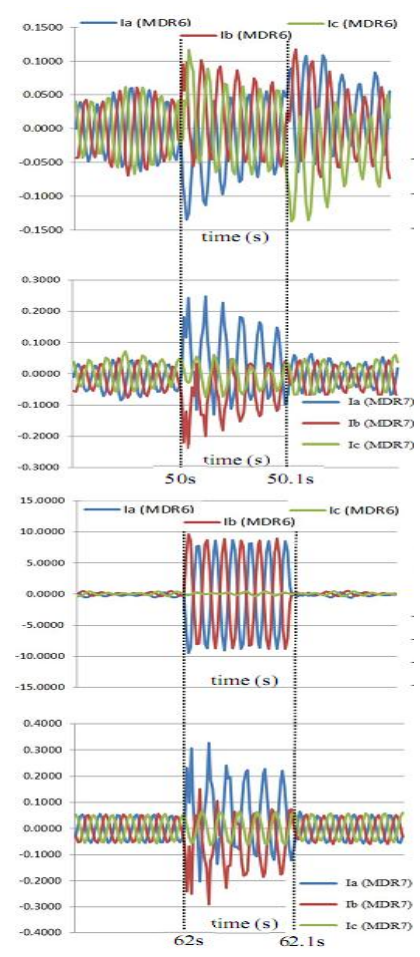

(e) $I_{a}, I_{b}$ and $I_{c}$ current components of MDR7 and MDR6 for a LL fault occurring at the $50^{\text {th }}$ and $62^{\text {nd }}$ seconds

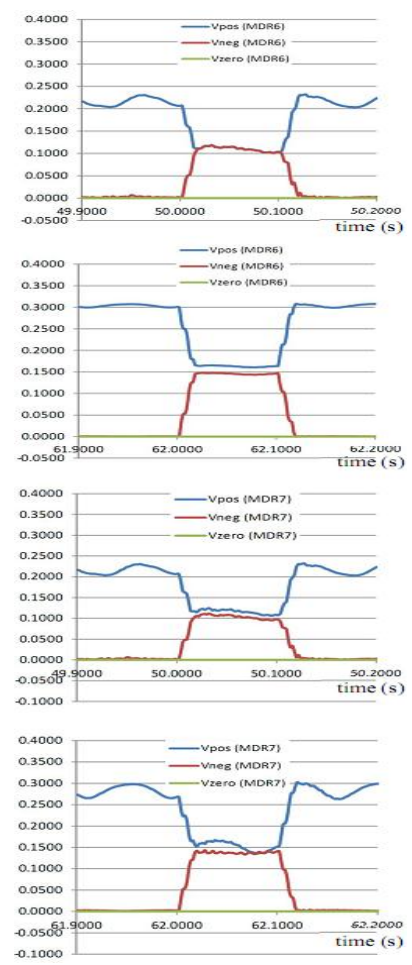

(c) $V_{\text {pos }}, V_{\text {neg, }}$, and $V_{\text {zero }}$ voltage components of MDR7 and MDR6 for a LL fault occurring at the $50^{\text {th }}$ $\& 62^{\text {nd }}$ seconds.

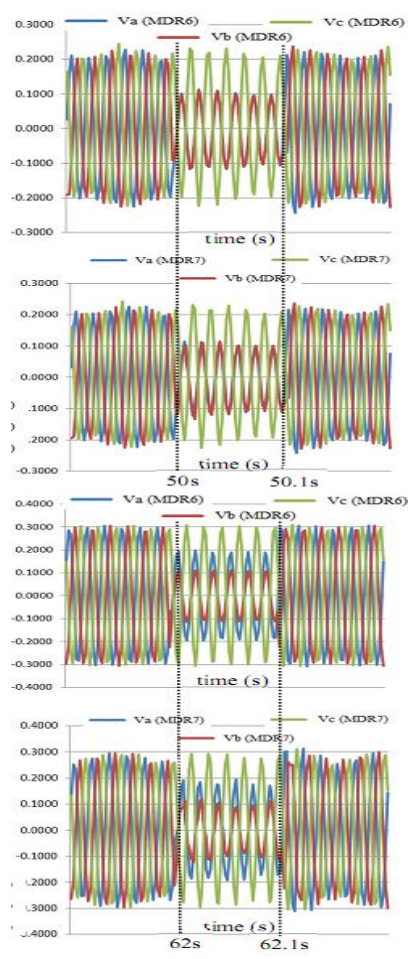

(f) $\quad V_{a}, \quad V_{b}$ and $\quad V_{c}$ voltage components of MDR7 and MDR6 for a LL fault occurring at the $50^{\text {th }}$ and $62^{\text {nd }}$ seconds

Fig. 4. Simulation results of a line-to-line (LL) fault occurring at the AC trunk line (F2) of a uni-grounded MG.

For a three-phase fault, positive/negative/zero sequence current and voltage components do not appear. 
Therefore, only THD values, phase-current and voltage parameters are used to detect a TP fault, referred to Fig. 3. See Fig. 4(c) \& Fig.4(d), parameters $I_{\text {zero }}$ and $V_{\text {zero }}$ cannot be used to detect LL faults in a uni-grounded microgrid. Phase currents and voltages, THD values of currents and voltages, parameters $I_{\text {pos }}, I_{\text {neg }}, V_{\text {pos }}, V_{\text {neg }}$, $3 I_{0}, 3 V_{0},\left|I_{\text {neg }}\right| /\left|I_{\text {pos }}\right|,\left|V_{\text {neg }}\right| /\left|V_{\text {pos }}\right|$ can be used to detect a LL fault at $\mathrm{F}_{2}$. If the penetration level of DG sources is large, primary fault protection of a uni-grounded microgrid can use an $I_{d}$ parameter. THD values, and phase current and voltage parameters are effectively used to determine which phases are faulted with regard to the LL faults, see Fig. 4(a), Fig. 4(b), Fig. 4(e), \& Fig. 4(f).

\subsubsection{Faults occurring at the $62^{\text {nd }}$ second at location $F_{2}$}

Micro-turbine, PV, and battery power conditioning systems operate at a grid-connected mode when faults occur at the $62^{\text {nd }}$ second. MDR6 is used to observe a fault current flowing from the grid to a faulted location $F_{2}$ in a uni-grounded LVAC microgrid, referred to Fig. 1. See Fig. 2(j), Fig. 3(c) and Fig. 4(e), the grid fault current values are very high so that MDR6 can use overcurrent protection principles to detect the faults at $\mathrm{F}_{2}$. On the other hand, MDR6 can use an $I_{d}$ parameter to detect SLG, TP and LL faults when a uni-grounded MG is synchronised to the utility grid. During the grid-connected operation mode of uni-grounded MGs, if loss of the grid synchronization (from the $61^{\text {st }}$ second to the $63^{\text {rd }}$ second) and fault occurrence (at the $62^{\text {nd }}$ second) happen at the same time, THD values, $E_{d}$ voltage, and positive/negative/zero sequence current and voltage components $\left(I_{\text {pos }}, I_{\text {neg }}, I_{\text {zero }}\right.$ and $V_{\text {pos }}, V_{\text {neg }}, V_{\text {zero }}$ ) are ineffective to be applied for fault protection systems, referred to Fig. 2(b), Fig. 2(c), Fig. 2(h), Fig. 2(e), Fig. 3(a) \& Fig. 3(b). A main reason is because their values are very high at both the synchronization loss and fault cases. Otherwise, if a uni-grounded AC MG gets synchronisation with the utility grid during the grid-connection operation duration, the aforementioned parameters can be properly applied for detecting faults at $\mathrm{F}_{2}$. For instance, see Fig. 4, the THD values, sequence current and voltage components are observed to accurately detect a line-to-line fault at $F_{2}$ at the $62^{\text {nd }}$ second.

\subsection{Faults at an $\mathrm{AC}$ Common Bus ( $\left.\mathrm{F}_{3-1}\right)$}

In case of various faults occurring at a location $\mathrm{F}_{3-1}$, referred to Fig. 1, MDR4, MDR5 \& MDR7 are used to detect the faults. Fault characteristics at an $\mathrm{AC}$ common bus $\left(\mathrm{F}_{3-1}\right)$ are similar to those at an $\mathrm{AC}$ trunk line $\left(\mathrm{F}_{2}\right)$ in a uni-grounded MG because an AC common bus can be understood as an AC trunk line if there are no any direct connection of load branches to the common bus surveyed. It is noticed that definition of the AC trunk line does not allow any load branches to be connected along its length. On the other hand, if an AC common bus contains load branches, direction of currents at the common bus is not changed during the bus faults and consequently, it is very difficult to determine where the faulted locations are. In order to solve this problem, the paper proposes that the load branches can be directly connected to the common bus only if these load branches are not placed between DG source branches also connected at the common bus. With the proposed placement of load branches, AC trunk lines and common buses have the same transient behaviours for different faults. This means that possible fault protection solutions of a trunk line can be properly applied for protection of an $\mathrm{AC}$ common bus and vice-versa. From the above reasons, parameters of $T H D_{I a}, T H D_{I b}, T H D_{I c}, T H D_{V a}, T H D_{V b}, T H D_{V c}, I_{p o s}, I_{\text {neg, }}, I_{\text {zero }}, V_{\text {pos }}, V_{\text {neg }}, V_{\text {zero }}, 3 I_{0}, 3 V_{0},\left|I_{\text {neg }}\right| /\left|I_{\text {pos }}\right|,\left|I_{z e r o}\right| /\left|I_{\text {pos }}\right|$, $\left(\left|I_{\text {neg }}\right|+\left|I_{\text {zero }}\right|\right) /\left|I_{\text {pos }}\right|,\left|V_{\text {neg }}\right| /\left|V_{\text {pos }}\right|,\left|V_{\text {zero }}\right| /\left|V_{\text {pos }}\right|,\left(\left|V_{\text {neg }}\right|+\left|V_{\text {zero }}\right|\right) /\left|V_{\text {pos }}\right|, E_{d,} I_{d}$, and $I_{d n}$ with respect to the faults at $\mathrm{F}_{3-1}$ are not necessary to be mentioned in this section, because their values are analysed under fault situations at an $\mathrm{AC}$ trunk line $\left(\mathrm{F}_{2}\right)$.

With SLG, TP, and LL faults at $\mathrm{F}_{3-1}$, current and voltage parameters at each phase $\left(I_{a}, I_{b}, I_{c}, V_{a}, V_{b}\right.$, and $\left.V_{c}\right)$ are observed at MDR4, MDR5, and MDR7 as shown in Fig. 5, Fig. 6, and Fig. 7. Considering these simulated parameters, major judgements are given as below:

- SLG, TP and LL faults occur at the 50 $0^{\text {th }}$ second time when a uni-grounded MG is working at an islanded mode, so fault current values are either low or high depending on two DG types (including 
inverter-based (IB) DGs and rotating-based DGs) penetrated into the uni-grounded MG. Referred to Fig. 1, all DG source branches are IBDG branches, so fault current at each branch is limited to $2 \mathrm{pu}$. Consequently, fault currents measured at MDR4, MDR5 and MDR7 are twice the rated load currents of PV, PCS, and MT branches, respectively, when the faults happen at the $50^{\text {th }}$ second at $F_{3-1}$, see Fig. 5-Fig. 7.

- If SLG, TP, and LL faults occur at the $62^{\text {nd }}$ second time when a uni-grounded MG is operating at a grid-connected mode, a grid fault current measured at MDR7 is very high (about 4 8 times the rated load current). Fault currents measured at MDR5 and MDR4 are twice the rated load currents of PCS and PV branches, respectively.

- During the grid-connected or islanded operation modes of a uni-grounded MG, after SLG, TP, and LL faults at a location $\mathrm{F}_{3-1}$ are cleared, currents and voltages measured at MDR4, MDR5, and MDR7 still continue to fluctuate in a certain time period before getting their steady states. The three-phase fault causes the highest fluctuation in currents and voltages in comparison with the SLG and LL faults. The significant fluctuation of currents and voltages after clearing the faults can be caused by control modes of inverters in IBDG branches or a time constant of LCL filters connected to DG inverters' outputs. Therefore, $3 I_{0}$ and $3 V_{0}$ based fault protection solutions should be carefully considered with regard to this fluctuation case.

- At the islanded operation mode, measured fault currents containing DC-offset components result in high peak fault-current values, but these peak current values are not high enough so that overcurrent protection devices placed at IBDG source branches are activated. This case is similarly seen at fault currents measured at MDR4 \& MDR5 during the grid-connected operation mode.

\subsection{Faults at a PV Source Branch $\left(F_{3-2}\right)$}

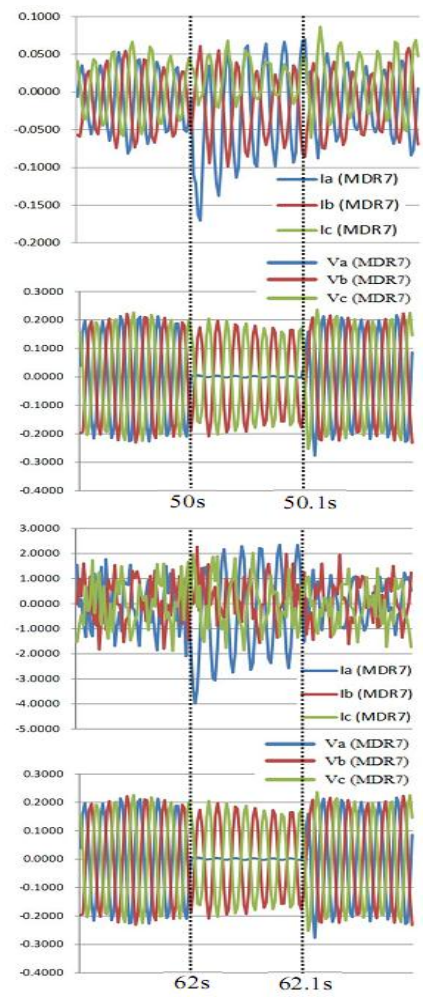

(a) Fault currents and voltages observed at MDR7 for a SLG fault at the $50^{\text {th }}$ and $62^{\text {nd }}$ seconds.
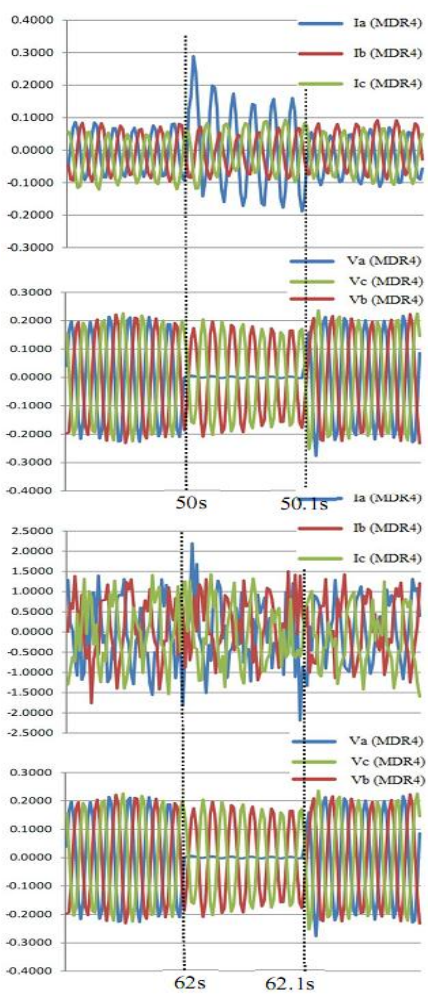

(b) Fault currents and voltages observed at MDR4 for a SLG fault at the $50^{\text {th }} \& 62^{\text {nd }}$ seconds.

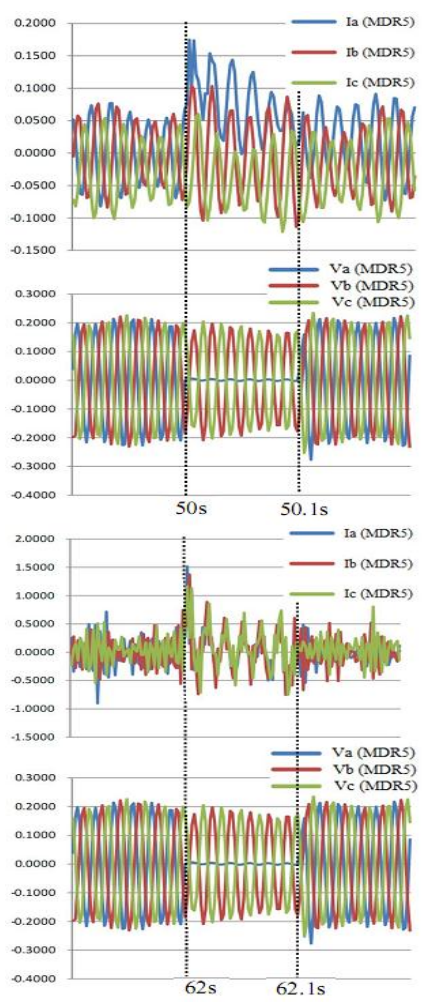

(c) Fault currents and voltages observed at MDR5 for a SLG fault at the $50^{\text {th }}$ and $62^{\text {nd }}$ seconds.

Fig. 5. Simulation results of a SLG fault occurring at an AC common bus. 


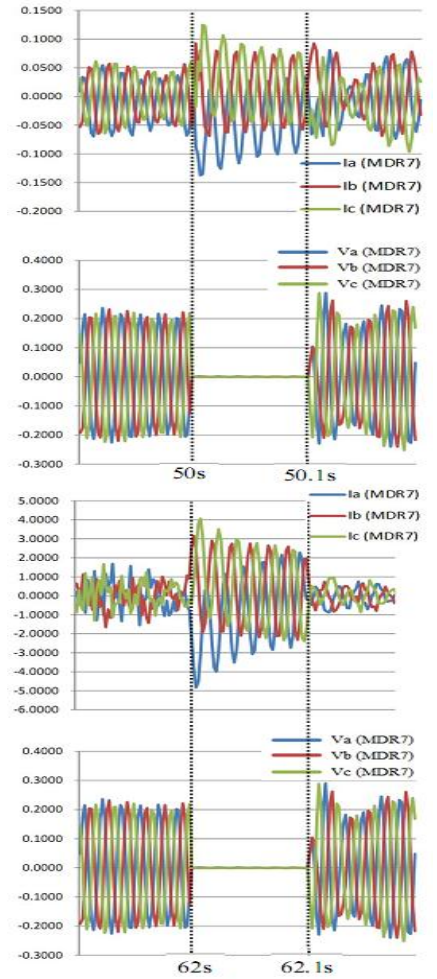

(a) Fault currents and voltages observed at MDR7 for a three-phase fault occurring at the $50^{\text {th }}$ and $62^{\text {nd }}$ seconds

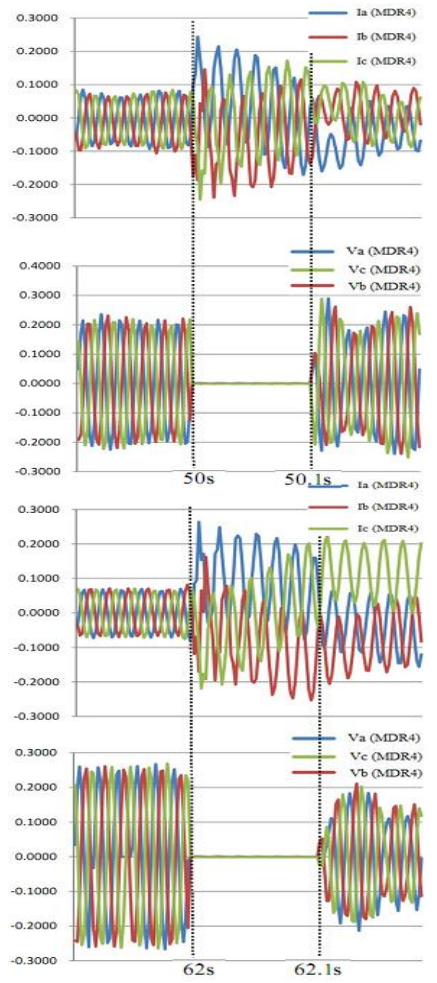

(b) Fault currents and voltages observed at MDR4 for a three-phase fault occurring at the $50^{\text {th }}$ and $62^{\text {nd }}$ seconds

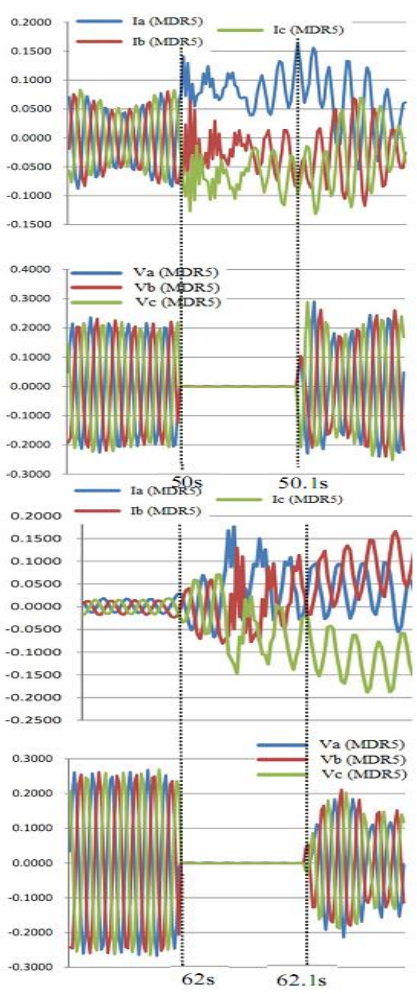

(c) Fault currents and voltages observed at MDR5 for a three-phase fault occurring at the $50^{\text {th }}$ and $62^{\text {nd }}$ seconds

Fig. 6. Simulation results of a three-phase fault occurring at an AC common bus (F3-1) of a uni-grounded microgrid.
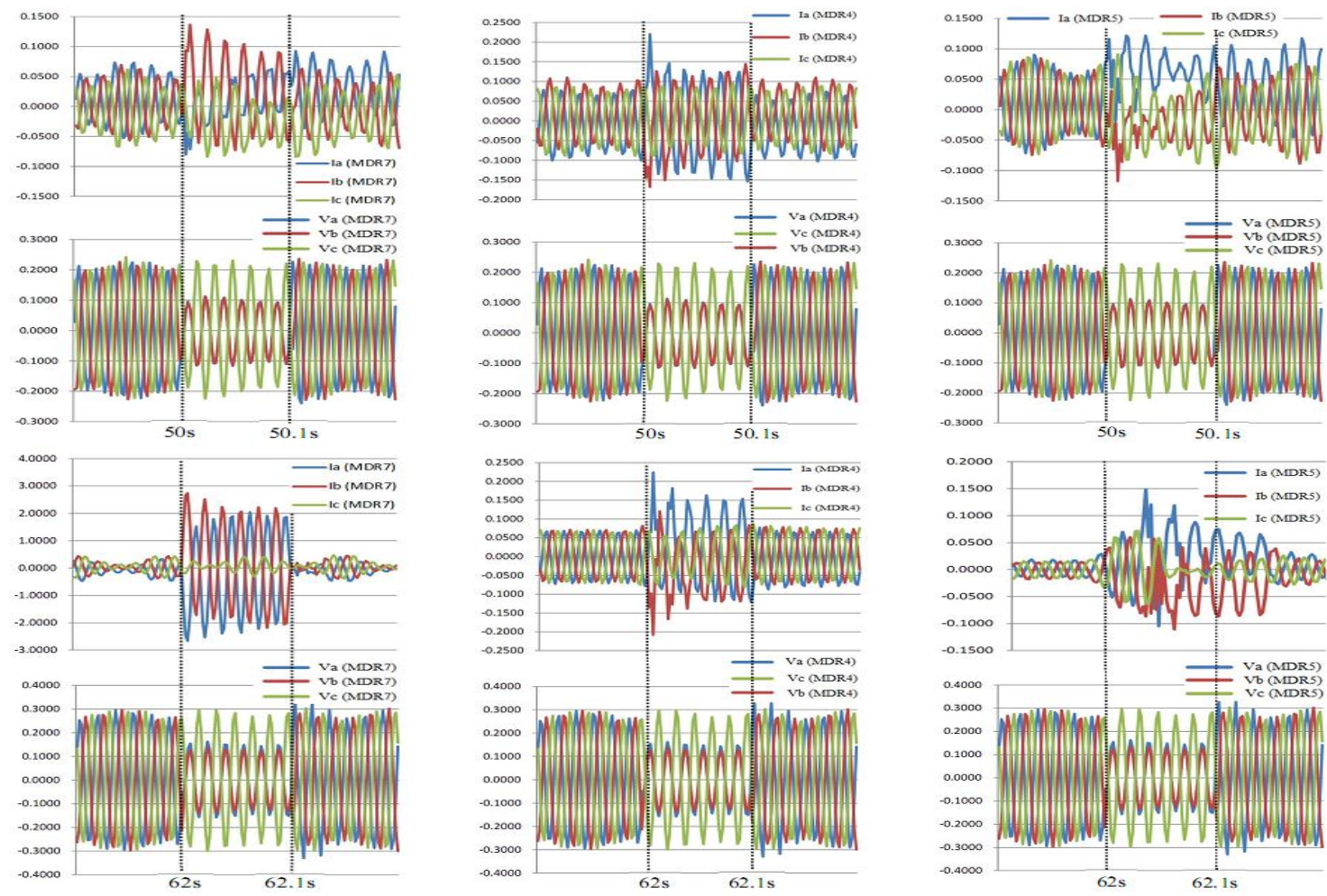

(a) Fault currents and voltages observed at MDR7 for a line-to-line fault occurring at $50^{\text {th }}$ and $62^{\text {nd }}$ seconds

(b) Fault currents and voltages observed at MDR4 for a line-to-line fault occurring at $50^{\text {th }}$ and $62^{\text {nd }}$ seconds

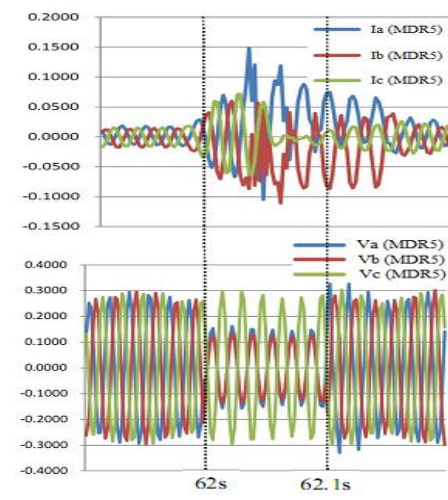

(c) Fault currents and voltages observed at MDR5 for a line-to-line fault occurring at $50^{\text {th }}$ and $62^{\text {nd }}$ seconds

Fig. 7. Simulation results of a line-to-line fault occurring at an AC common bus (F3-1) of a uni-grounded MG. 
When various faults occur at a PV source branch $\left(\mathrm{F}_{3-2}\right)$ in a uni-grounded AC MG, MDR4 is used to protect this PV source branch, see Fig. 1. Output parameters of a DC/AC power inverter at the PV branch are also observed. Parameters measured at the PV inverter's output (IO) and MDR4 are $I_{a}, I_{b}, I_{c}, V_{a}, V_{b}, V_{c}, T H D_{I a}$, $T H D_{I b}, T H D_{I c}, T H D_{V a}, T H D_{V b}, T H D_{V c}, I_{\text {pos }}, I_{\text {neg }}, I_{\text {zero }}, V_{\text {pos }}, V_{\text {neg }}, V_{\text {zero }}, 3 I_{0}, 3 V_{0},\left|I_{\text {neg }}\right| /\left|I_{\text {pos }}\right|,\left|I_{\text {zero }}\right| /\left|I_{\text {pos }}\right|$, $\left(\left|I_{\text {neg }}\right|+\left|I_{\text {zero }}\right|\right) /\left|I_{\text {pos }}\right|,\left|V_{\text {neg }}\right| /\left|V_{\text {pos }}\right|,\left|V_{\text {zero }}\right| /\left|V_{\text {pos }}\right|,\left(\left|V_{\text {neg }}\right|+\left|V_{\text {zero }}\right|\right) /\left|V_{\text {pos }}\right|,\left(\left|I_{\text {max }}\right|-\left|I_{\text {min }}\right|\right) /\left|I_{\text {avg }}\right|\left(I_{\text {max }}=\max \left(\left|I_{a}\right| ;\left|I_{b}\right| ;\right.\right.$ $\left.\left|I_{c}\right|\right) ; I_{\min }=\min \left(\left|I_{a}\right| ;\left|I_{b}\right| ;\left|I_{c}\right|\right)$; and $I_{\text {avg }}=$ average $\left.\left(\left|I_{a}\right| ;\left|I_{b}\right| ;\left|I_{c}\right|\right)\right), I_{d}$ and $I_{d n}$. Fig. 8, Fig. 9, and Fig. 10 indicate simulation results of the aforementioned parameters with respect to SLG, TP, and LL faults, respectively, occurring at a location $\mathrm{F}_{3-2}$ in a uni-grounded $380 \mathrm{~V}$ AC MG. The faults occur at the $50^{\text {th }}$ and $62^{\text {nd }}$ seconds, and the fault time is $0.1 \mathrm{~s}$.

\subsubsection{Faults occurring at the $\mathbf{5 0}^{\text {th }}$ second at a location $\mathbf{F}_{3-2}$}

At the $50^{\text {th }}$ second time, a simulated uni-grounded $M G$ is operating at an islanded mode.

- See Fig. 8(a), 3Io and $3 V_{0}$ components can be applied for detecting the SLG fault at $\mathrm{F}_{3-2 .}$. At the PV inverter's output, after clearing the SLG fault, a voltage unbalance still persists in a short-time period (about 5-10cycles) leading to a very high $3 V_{0}$ value, which can cause mis-operation of a $3 V_{0}$ based fault protection solution for the inverter at an IBDG source branch like a PV source branch in the uni-grounded MG. Voltage unbalance at a PV inverter's output can be resulted from V-f control modes of the inverter or time constant of a LCL filter. Therefore, $3 I_{0}$ and $3 V_{0}$ components are only applied for the back-up protection of inverters at IBDG branches.

- See Fig. 8(b)-(c) and Fig. 10(a)-(d), negative sequence current and voltage components $\left(I_{\text {neg, }}\left|I_{\text {neg }}\right| /\left|I_{\text {pos }}\right|\right.$, $\left.\left(\left|I_{\text {neg }}\right|+\left|I_{\text {zero }}\right|\right) /\left|I_{\text {pos }}\right|, V_{\text {neg, }},\left|V_{\text {neg }}\right| /\left|V_{\text {pos }}\right|,\left(\left|V_{\text {neg }}\right|+\left|V_{\text {zero }}\right|\right) /\left|V_{\text {pos }}\right|\right)$ can be effectively used for SLG and LL fault protection methods in a uni-grounded MG. Otherwise, $I_{\text {zero }}$ and $V_{\text {zero }}$ based protection solutions are non-effective to detect the SLG and LL faults. A PV source branch uses a $\Delta / Y$ isolation transformer, so MDR4 placed at a Y side of the transformer cannot detect the zero-sequence current component with respect to a faulted location $\mathrm{F}_{3-2}$ at a $\Delta$ side of the transformer. However, in case of a SLG fault at $\mathrm{F}_{3-2}$, a PV inverter can use $I_{\text {zero }}$ and $V_{\text {zero }}$ based protection solutions to detect the fault. This is because the ground fault current can flow into the inverter through the grounded middle-point of DC capacitors at a DC side of the PV inverter.

- See Fig. 8(d)-(e), Fig. 9(a)-(b), and Fig. 10(e)-(f), THD components of phase-currents and phase-voltages are effectively used for balanced/unbalanced fault protection systems. Moreover, the protection systems using THD components can be considered as primary protection systems of uni-grounded MGs. A significant difference in values of THD components from a normal operation mode to a faulted operation mode of the uni-grounded MG is a basic protection principle to detect various faults. To identify the faulted phases from unbalanced/balanced fault cases, both current and voltage THD components are used. Concretely, a phase is faulted only if its current and voltage THD values are higher than the values at healthy phases. It is noted that the balanced faults are identified only the current and voltage THD values at three phases are very high and nearly equal, referred to Fig. 9(a)-Fig. 9(b). Besides that, if current and voltage THD values at any two of three phases are approximately equal and many times higher than one remaining phase, phase-to-phase or double-phase to ground faults are identified in the uni-grounded MG, referred to Fig. 10(e)-(f). Lastly, if only one of three phases has both high current and voltage THD values, a SLG fault is determined.

- Use of an $I_{d n}$ parameter is suitable for detecting ground faults at the PV inverter's output. However, the $I_{d n}$ parameter measured at MDR4 is zero because a simulated microgrid is uni-grounded at a distribution transformer and uses a three-phase and four-wire system. An $I_{d}$ parameter $\left(\left|I_{d}\right|=\left|I_{a}\right|+\left|I_{b}\right|+\left|I_{c}\right|\right)$ is only used for a back-up solution to detect SLG, TP and LL faults, because the $I_{d}$ value depends on limited fault currents from IBDG branches and a penetration level of IBDGs into the uni-grounded MG. At an islanded operation mode of the uni-grounded microgrid, change in the $I_{d}$ value 
is insignificant when the faults occur, so it is not easy to differentiate between change in the $I_{d}$ value caused by the faults and change in the $I_{d}$ value caused by dynamic situations (e.g. load power change, motor starting). Consequently, false tripping can occur in an $I_{d}$ based fault protection system.

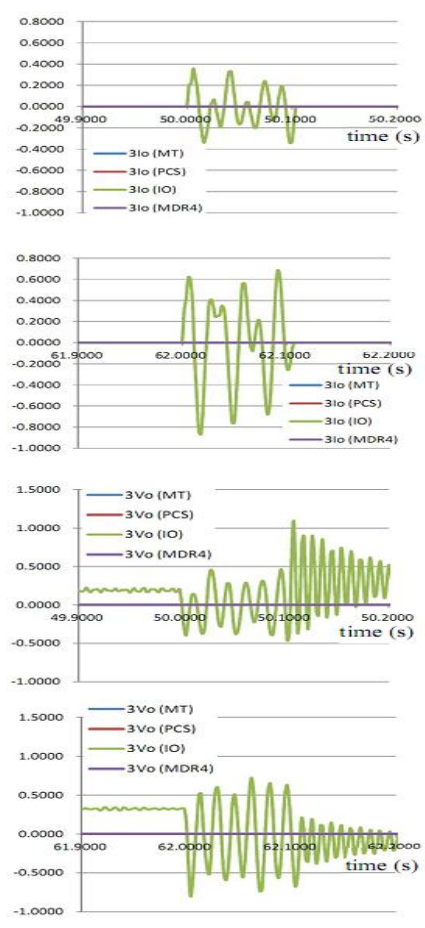

(a) $3 \mathrm{I0}$ and $3 \mathrm{~V} 0$ components measured at MDR4 and the IO for a SLG fault occurring at the $50^{\text {th }}$ and $62^{\text {nd }}$ seconds.

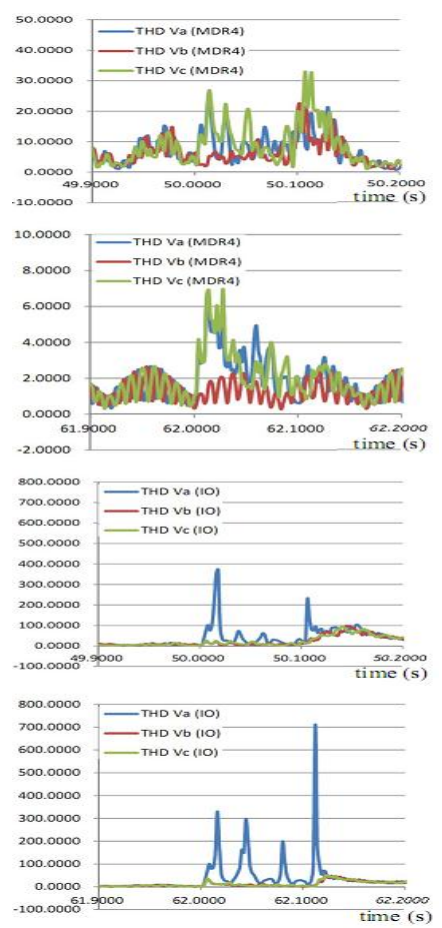

(d) $T H D_{V a}, T H D_{V b}$ and $T H D_{V c}$ measured at MDR4 and the IO for a SLG fault occurring at the $50^{\text {th }}$ and $62^{\text {nd }}$ seconds.
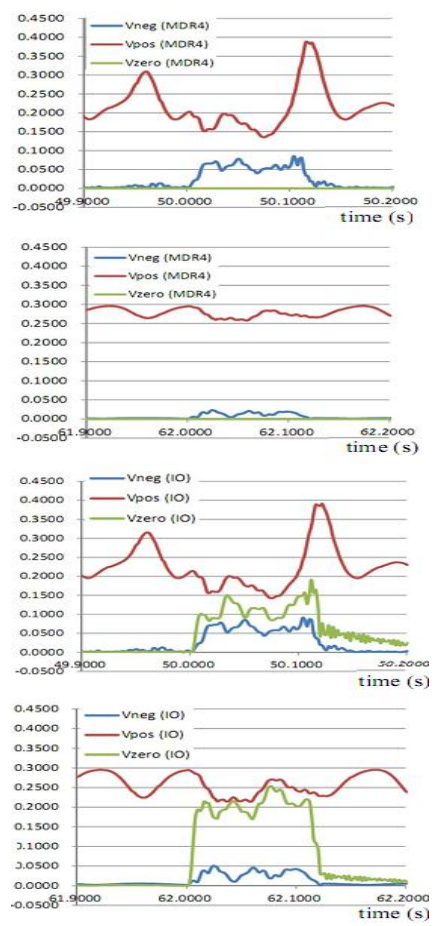

(b) Vpos, Vneg, and Vzero components measured at MDR4 and the IO for a SLG fault occurring at the $50^{\text {th }}$ and $62^{\text {nd }}$ seconds.

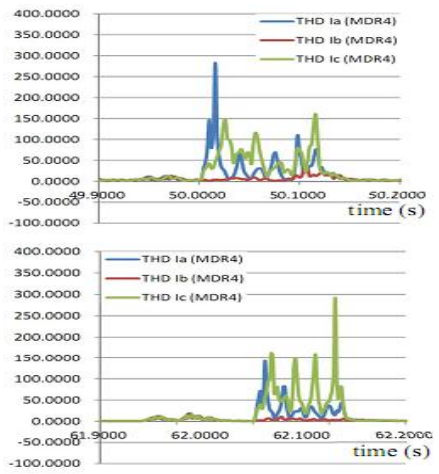

350.0000 二Tно та (10)

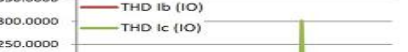

250.0000

200.0000

150.0000
50.000000
5.0000
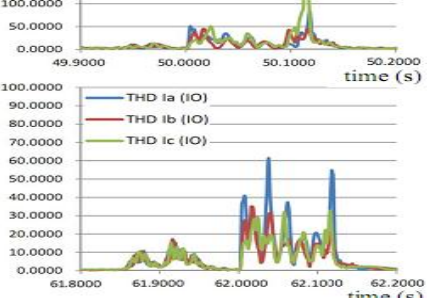

(e) $T H D_{I a}, T H D_{l b} \& T H D_{l c}$ measured at MDR4 and the IO for a SLG fault occurring at $50^{\text {th }}$ and $62^{\text {nd }}$ seconds.
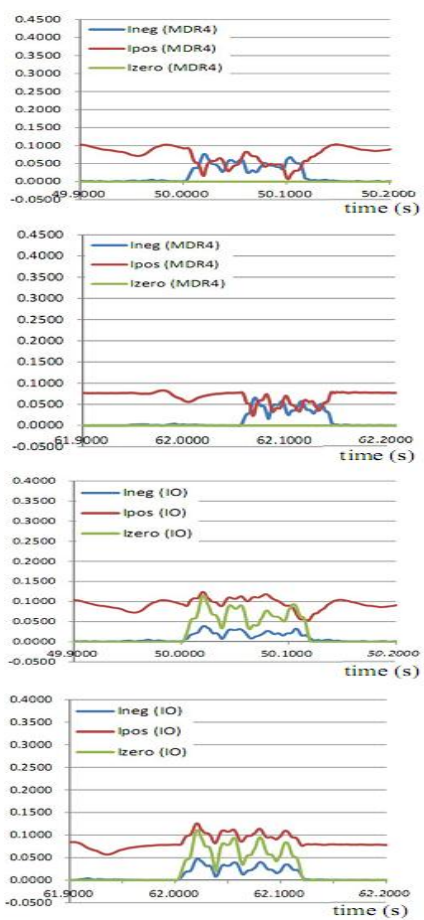

(c) Ipos, Ineg, and Izero components measured at MDR4 and the IO for a SPG fault occurring at the $50^{\text {th }}$ and $62^{\text {nd }}$ seconds.

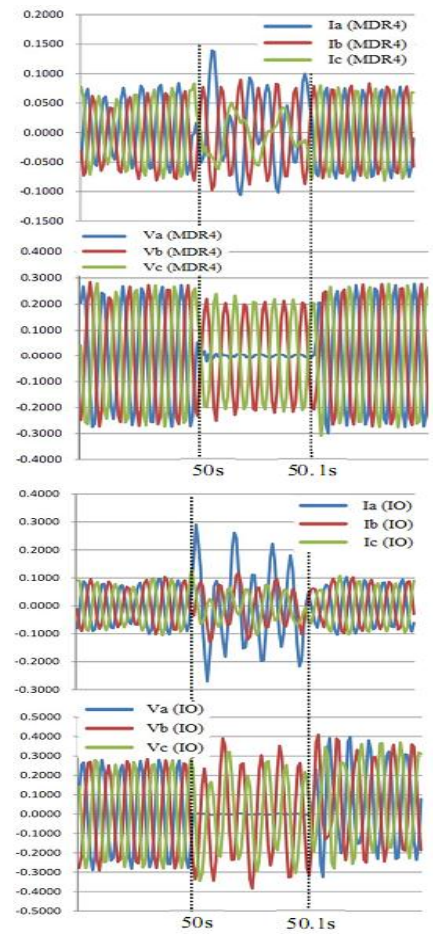

(f) $I_{a}, I_{b}, I_{c}, V_{a}, V_{b}$, and $V_{c}$ parameters measured at MDR4 and the IO for a SLG fault occurring at the $50^{\text {th }}$ second.

Fig. 8. Simulation results of a single-line to ground (SLG) fault occurring at a PV source branch (F3-2) of a uni-grounded 380V AC microgrid. 
- A $\left(\left|I_{\max }\right|-\left|I_{\min }\right|\right) /\left|I_{\text {avg }}\right|$ parameter is not used for detecting faults at $\mathrm{F}_{3-2}$ because of the inconsiderable change in its values when the faults occur, referred to Fig. 9(c) \& Fig. 10 (g).

- During the autonomous operation mode of a uni-grounded MG surveyed, when faults occur at a location $\mathrm{F}_{3-2}$ in the PV source branch, MDR4 will observe fault currents flowing from a MT system and a battery power conditioning system, see Fig. 8(f), Fig. 9(d)-(f), Fig. 10(h)-(i). A peak fault current value measured at the PV inverter's output is 2 3 times a rated current to avoid damage of the inverter. The peak fault current measured at MDR4 is about 3 4 times higher than a rated load current, which consists of partial fault currents caused by MT and battery systems.

- When SLG, TP, and LL faults are cleared, three-phase current/voltage unbalance still persists in the uni-grounded microgrid. After next 15 20 cycles, microgrid currents and voltages will get their balance states, see Fig. 9(d) \& Fig. 9(e).

\subsubsection{Faults occurring at the $62^{\text {nd }}$ second at a location $\mathbf{F}_{3-2}$}

At the $62^{\text {nd }}$ second time, a uni-grounded $M G$ is operating at the grid-connected mode, simulation results are analysed as below:

- $3 I_{0}$ and $3 V_{0}$ components are only used for the back-up fault protection of inverters at the grid-connected mode.

- Protection solutions based on negative-sequence current and voltage components are optimal to detect unbalanced faults at $\mathrm{F}_{3-2}$ in order to protect IBDG source branches. An inverter at an IBDG branch can use zero-sequence current and voltage components to detect ground faults (e.g. single-phase to ground, double-phase to ground, or three-phase to ground faults) because a middle-point of DC capacitors at a DC side of the inverter is grounded.

- THD components of phase currents and voltages are effectively used for balanced/unbalanced fault protection methods at the grid-connected mode of uni-grounded MGs.

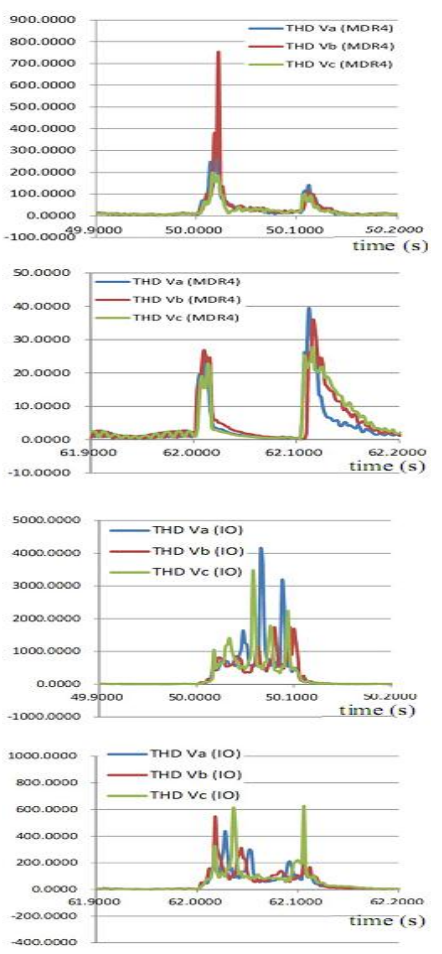

(a) $T H D_{V a}, T H D_{v b}$ and $T H D_{v c}$ measured at MDR4 and the IO for a TP fault occurring at the $50^{\text {th }}$ and $62^{\text {nd }}$ seconds.

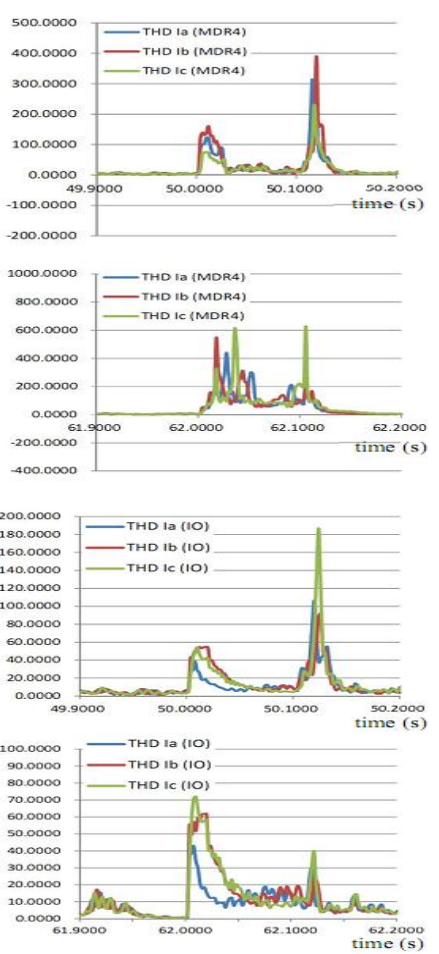

(b) $T H D_{I a}, T H D_{I b}$ and $T H D_{I c}$ measured at MDR4 and the IO for a TP fault occurring at the $50^{\text {th }}$ and $62^{\text {nd }}$ seconds.
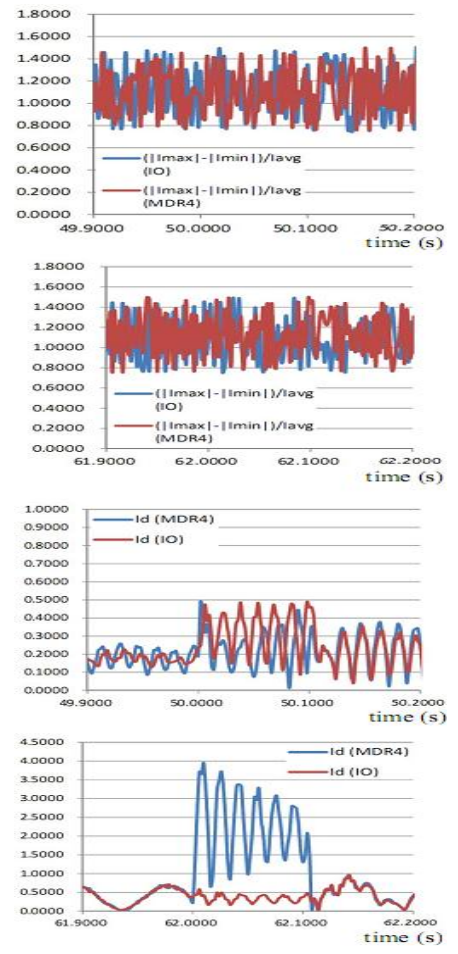

(c) $I_{d}$ and $\left(\left|I_{\max }\right|-\left|I_{\min }\right|\right) /\left|I_{\text {avg }}\right|$ parameters measured at MDR4 and the IO for a TP fault occurring at the $50^{\text {th }}$ and $62^{\text {nd }}$ seconds. 


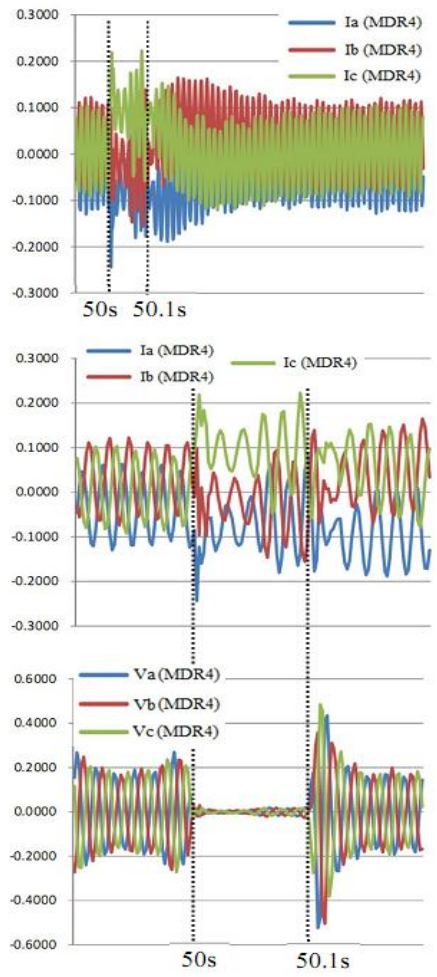

(d) $I_{a}, I_{b}, I_{c}, V_{a}, V_{b}$, and $V_{c}$ parameters measured at MDR4 for a TP fault occurring at the $50^{\text {th }}$ second.

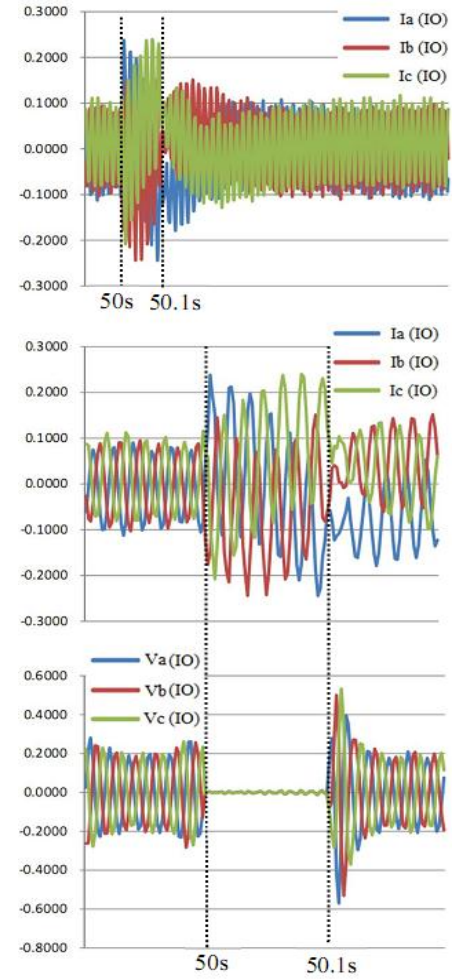

(e) $I_{a}, I_{b}, I_{c}, V_{a}, V_{b}$, and $V_{c}$ parameters measured at the inverter's output (IO) for a TP fault at the $50^{\text {th }}$ second.
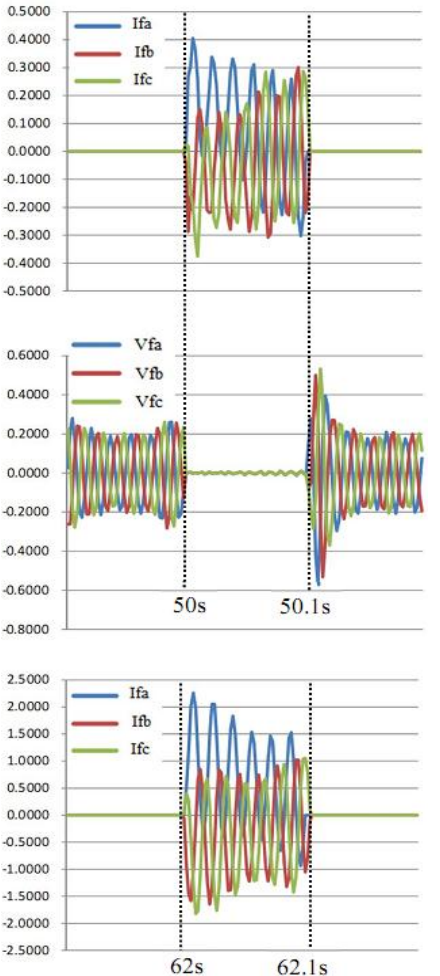

(f) $I_{f a}, I_{f b}, I_{f c}, V_{f a}, V_{f b}$, and $V_{f c}$ TP fault currents and voltages measured at a $\mathrm{F}_{3-2}$ location at the $50^{\text {th }}$ and $62^{\text {nd }}$ seconds.

Fig. 9. Simulation results of a three-phase (TP) fault occurring at a PV source branch (F3-2) of a uni-grounded 380V AC microgrid.
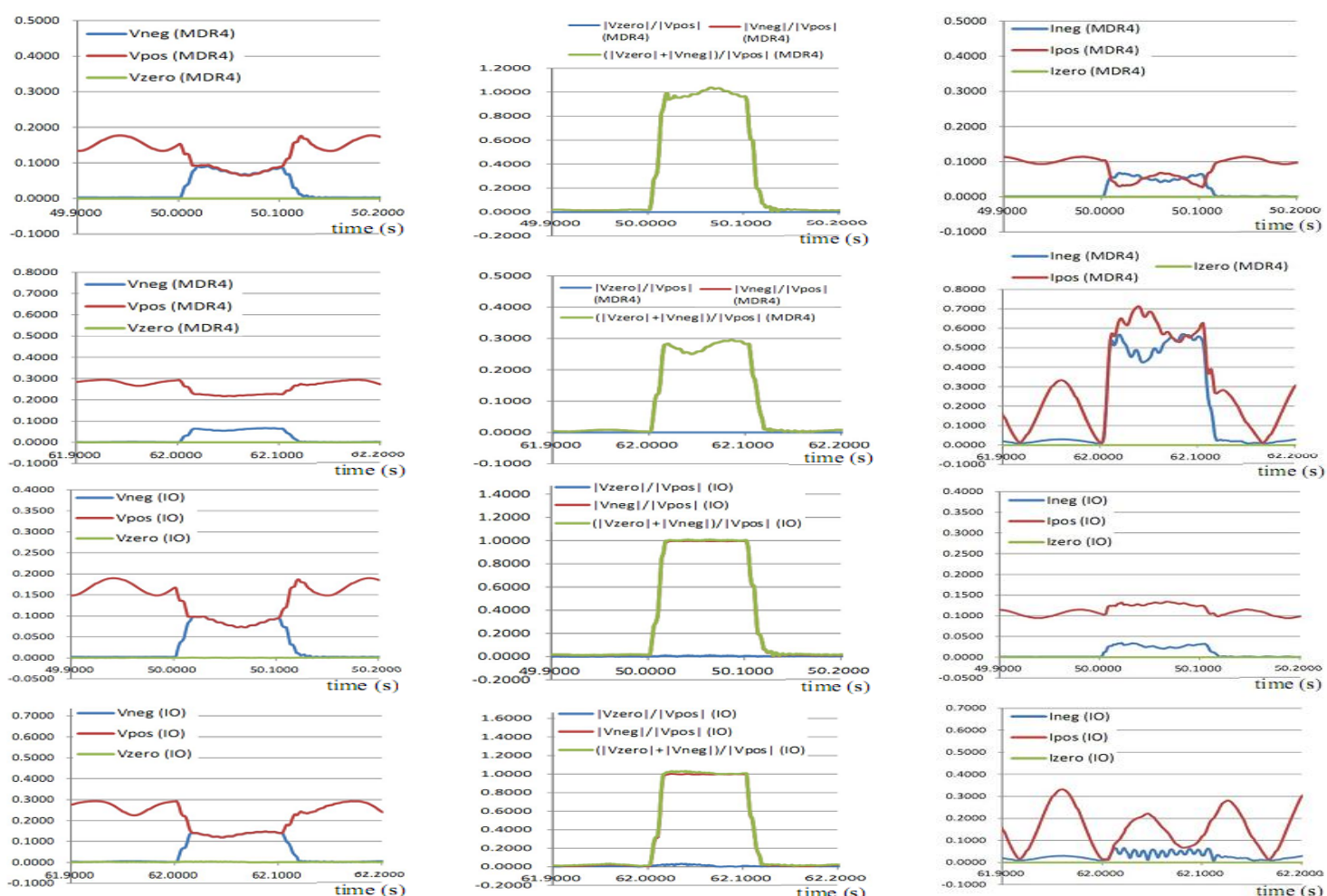

(a) $V_{\text {pos, }}, V_{\text {neg, }}$, and $V_{\text {zero }}$ parameters measured at the MDR4 and the IO for a LL fault occurring at $50^{\text {th }}$ and $62^{\text {nd }}$ seconds.

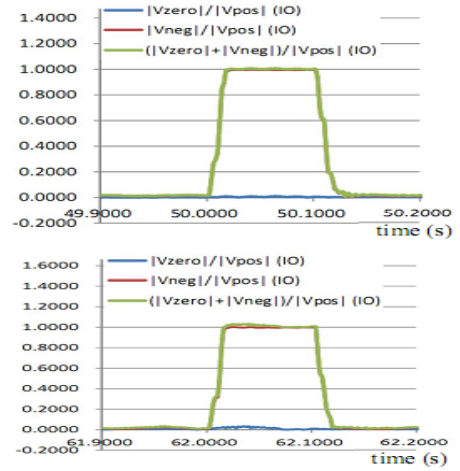

(b) $\left(\left|V_{\text {neg }}\right|+\mid V_{\text {zero }} /\right) /\left|V_{\text {pos }}\right|, \quad\left|V_{\text {neg }}\right| /\left|V_{\text {pos }}\right|$, $\left|V_{\text {zero }}\right| /\left|V_{\text {pos }}\right|$ parameters measured at MDR4 and the IO for a LL fault occurring at $50^{\text {th }}$ and $62^{\text {nd }}$ seconds.

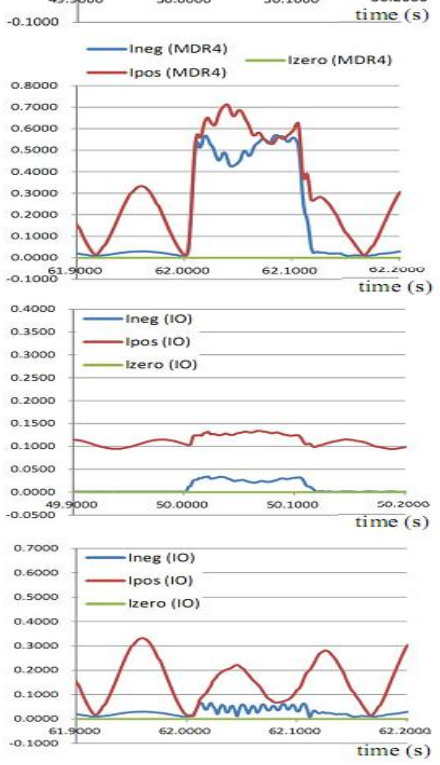

(c) $I_{\text {pos, }}, I_{\text {neg, }}$ and $I_{\text {zero }}$ parameters measured at the MDR4 and the IO for a LL fault occurring at $50^{\text {th }}$ and $62^{\text {nd }}$ seconds. 


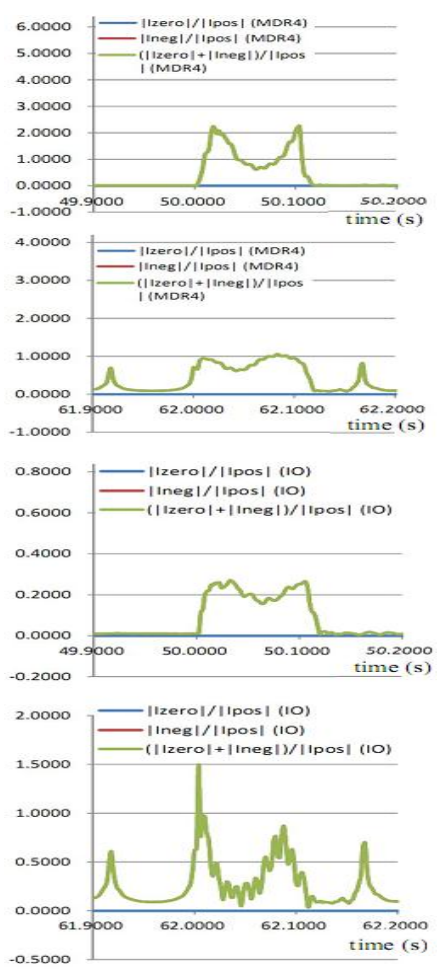

(d) $\quad\left(\left|I_{\text {neg }}\right|+\mid I_{\text {zero }} /\right) /\left|I_{\text {pos }}\right|, \quad\left|I_{\text {neg }}\right| /\left|I_{\text {pos }}\right|$, $\left|I_{\text {zero }}\right| /\left|I_{\text {pos }}\right|$ parameters measured at the MDR4 and the IO for a LL fault occurring at $50^{\text {th }}$ and $62^{\text {nd }}$ seconds.

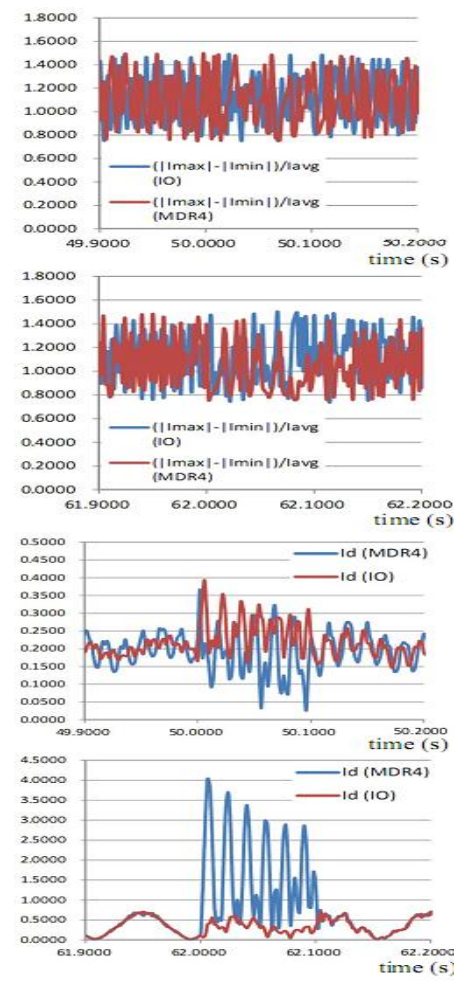

(g) $I_{d}$ and $\left(\left|I_{\max }\right|-\left|I_{\min }\right|\right) /\left|I_{\text {avg }}\right|$ parameters measured at the MDR 4 and the IO for a LL fault occurring at $50^{\text {th }}$ and $62^{\text {nd }}$ seconds
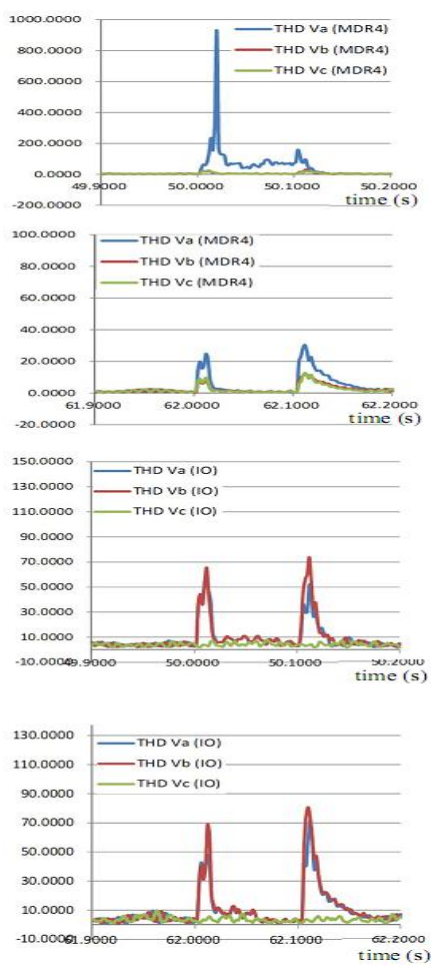

(e) $T H D_{V a}, \quad T H D_{V b}$ and $T H D_{V c}$ components measured at the MDR4 and the IO for a LL fault occurring at the $50^{\text {th }}$ and $62^{\text {nd }}$ seconds.

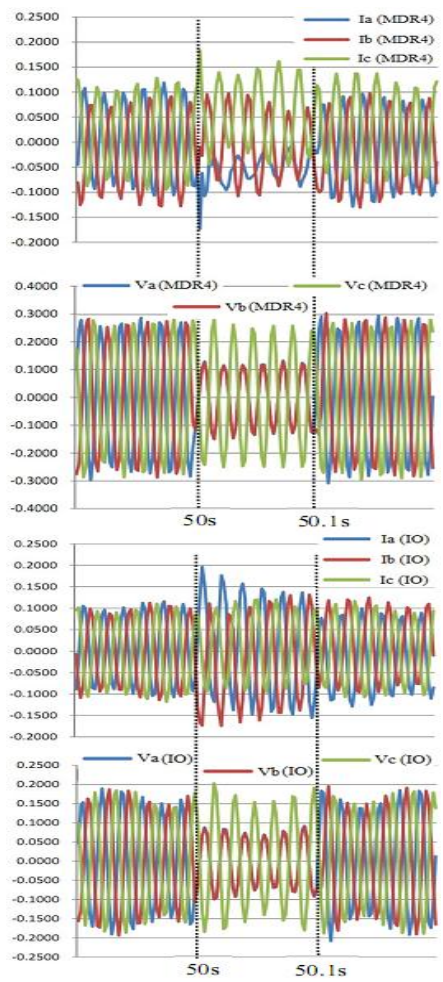

(h) $I_{a}, I_{b}, I_{c}, V_{a}, V_{b}$, and $V_{c}$ current and voltage parameters measured at the MDR4 and the IO for a LL fault occurring at the $50^{\text {th }}$ second
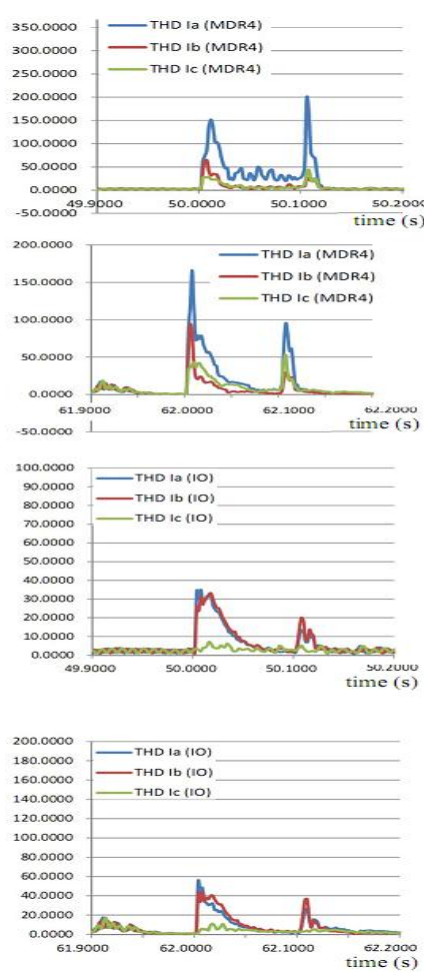

(f) $T H D_{I a}, T H D_{I b}$ and $T H D_{I c}$ components measured at the MDR4 and the IO for a LL fault occurring at the $50^{\text {th }}$ and $62^{\text {nd }}$ seconds.

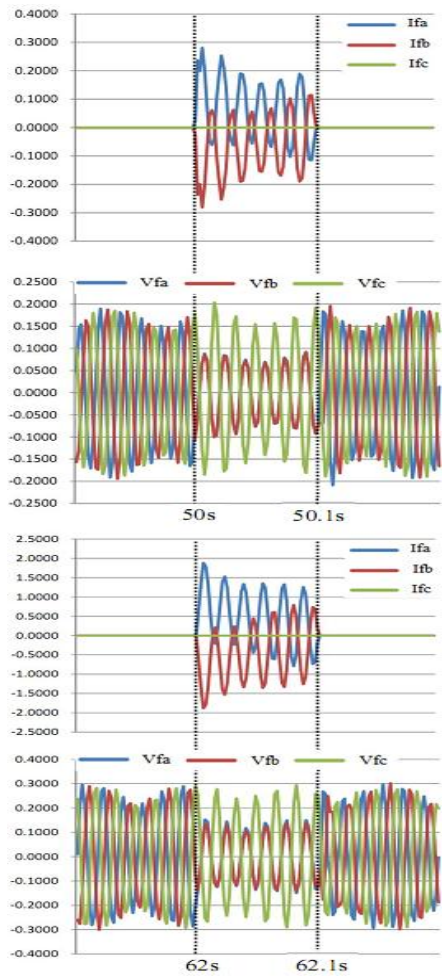

(i) $I_{f a}, I_{f b}, I_{f c}, V_{f a}, V_{f b}$, and $V_{f c}$ LL fault current and voltage parameters measured at a location $\mathrm{F}_{3-2}$ at the $50^{\text {th }}$ and $62^{\text {nd }}$ seconds

Fig. 10. Simulation results of a line-to-line (LL) fault occurring at a PV source branch (F3-2) of a uni-grounded 380V AC microgrid. 
- At the grid-connected operation mode, MDR4 can properly use an $I_{d}$ parameter for primary fault protection of DG source branches because a grid fault current flowing into a faulted DG source branch is very large. Change in the $I_{d}$ current value is very high when the faults occur, refer to Fig. 9(c) \& Fig. $10(\mathrm{~g})$.

- $\left(\left|I_{\max }\right|-\left|I_{\min }\right|\right) /\left|I_{\text {avg }}\right|$ ratio can be not used for detecting SLG, TP, and LL faults because of an inconsiderable change in its value when the faults occur, refer to Fig. 9(c) and Fig. 10 (g).

- Fault current flowing from the grid to $\mathrm{F}_{3-2}$ observed at MDR4 is large so that overcurrent protection solutions are effective for MDR4 to detect different faults at $\mathrm{F}_{3-2}$.

\subsection{Operation Transition of a Uni-Grounded 380V AC Microgrid}

Comparing a three-phase fault occurring at a PV source branch $\left(\mathrm{F}_{3-2}\right)$ at the time of $50^{\text {th }}$ second with an operation transition test of the uni-grounded MG from an islanded mode into a grid-connected mode at the time of $60^{\text {th }}$ second, referred to Fig. 11, the microgrid voltage is an important parameter used to differentiate between a fault situation and a MG operation transition case. For the islanded operation mode, the PV source branch works at a V-f control mode. For the grid-connected operation mode, the PV source works at a P-Q control mode. If a uni-grounded microgrid has its operation transition, output current of the PV source branch can be significantly fluctuated while the microgrid voltage can be stabilised due to the V-f control at the islanded operation mode or due to the grid voltage at the grid-connected operation mode. In Fig. 11, the PV output voltage insignificantly changes during the operation transition of a uni-grounded $380 \mathrm{~V}$ AC microgrid at the $60^{\text {th }}$ second, whereas the PV voltage gets nearly zero with respect to a three-phase fault occurring at the $50^{\text {th }}$ second. On the other hand, if faults occur at $A C$ common buses $\left(\mathrm{F}_{3-1}\right)$ or trunk lines $\left(\mathrm{F}_{2}\right)$, fluctuation of currents and voltages between the faults and the MG's operation transition cases can be analysed similarly to the faults at the PV source branch $\left(\mathrm{F}_{3-2}\right)$.

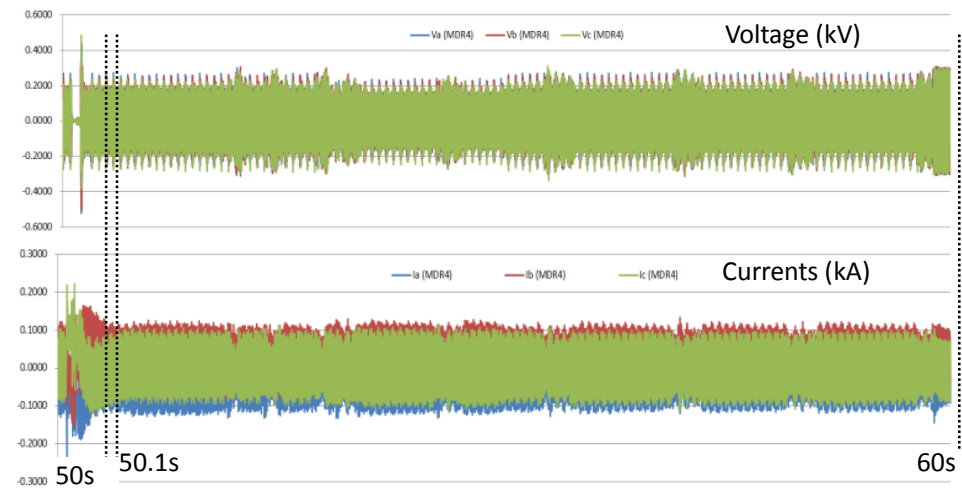

Fig. 11. Current and voltage parameters measured at MDR4 for a three-phase fault occurring at a PV source branch and an operation transition test of the uni-grounded 380V AC microgrid.

\section{Appropriate Fault Protection Solutions for a Uni-Grounded LVAC Microgrid}

Based on transient simulation results of a typical uni-grounded microgrid, available fault protection solutions corresponding to each different protection zone in a uni-grounded microgrid are mentioned, as shown Table 1. For each individual protection zone, main and back-up fault protection methods are proposed to ensure stable-reliable-adaptable-scalable operation of a uni-grounded MG. Protection coordination strategies (e.g. time-grading, communication system based coordination strategies) are needed to coordinate primary and back-up protection systems as well as primary and back-up protective devices in a uni-grounded LVAC microgrid. 
Table 1. Appropriate Fault Protection Solutions for a Uni-Grounded LVAC Microgrid with Six Individual Protection Zones

\begin{tabular}{|c|c|}
\hline \multicolumn{2}{|c|}{ Protection Zone 1 - Fault protection of AC generators and energy storage devices [5] } \\
\hline \multicolumn{2}{|l|}{ At both grid-connected and islanded operation modes } \\
\hline Main protection & Back-up protection \\
\hline $\begin{array}{l}\text { - Instantaneous overcurrent protection at phase and neutral } \\
\text { lines }(50 / 50 \mathrm{~N}) \\
\text { - Time overcurrent protection at phase and neutral lines } \\
(51 / 51 \mathrm{~N}) \text { and a grounded line }(51 \mathrm{G}) \\
\text { - Voltage-restrained time overcurrent }(51 \mathrm{~V}) \\
\text { - Differential protection (87) } \\
\text { - Under-voltage (27) and over-voltage protection (59) } \\
\text { - Negative-sequence overcurrent protection (46) }\end{array}$ & $\begin{array}{l}\text { - Over-/under-frequency }(810 / \mathrm{U}) \\
\text { - Loss of excitation }(40) \\
\text { - Synchronization check (25) }\end{array}$ \\
\hline \multicolumn{2}{|c|}{ Protection Zone 2 - Fault protection of isolation and distribution transformers [5] } \\
\hline \multicolumn{2}{|l|}{ At both grid-connected and islanded operation modes } \\
\hline Main protection & Back-up protection \\
\hline $\begin{array}{l}\text { - Phase-current based differential protection }(87 \mathrm{~T}) \\
\text { - Time-overcurrent protection at phase and neutral lines } \\
(51 / 51 \mathrm{~N}) \\
\text { - Instantaneous overcurrent protection at phase and neutral } \\
\text { lines }(50 / 50 \mathrm{~N})\end{array}$ & $\begin{array}{l}\text { - Under-voltage (27) } \\
\text { - Over-voltage (59) }\end{array}$ \\
\hline
\end{tabular}

Protection Zone 3 - Fault protection of power converters

\begin{tabular}{|c|c|c|c|}
\hline \multicolumn{2}{|c|}{ At the grid-connected operation mode } & \multicolumn{2}{|c|}{ At the islanded operation mode } \\
\hline Main protection & Back-up protection & Main protection & Back-up protection \\
\hline $\begin{array}{l}\text { - THD values of currents and } \\
\text { voltages } \\
\text { - Protective relays use } \\
\text { negative-sequence current and } \\
\text { voltage components }(46,47), \\
\text { the ratios }\left|I_{\text {neg }}\right| /\left|I_{\text {pos }}\right| \\
\left|V_{\text {neg }}\right| /\left|V_{\text {pos }}\right|,\left(\left|I_{\text {neg }}\right|+\left|I_{\text {zero }}\right|\right) /\left|I_{\text {pos }}\right| \\
\text { or }\left(\left|V_{\text {neg }}\right|+\left|V_{\text {zero }}\right|\right) /\left|V_{\text {pos }}\right| \\
\text { - Use of the parameter } I_{d}\end{array}$ & $\begin{array}{l}\text { - Under-voltage } \\
\text { protection } \\
\text { - Under-/over- } \\
\text { frequency protection } \\
(81 \mathrm{U} / 0) \\
\text { - Use of } 3 I_{0} \text { and } 3 V_{0} \\
\text { values }\end{array}$ & $\begin{array}{l}\text { - THD values of currents \& } \\
\text { voltages } \\
\text { - Relays use } \\
\text { negative-sequence } \\
\text { current and voltage } \\
\text { components }(46,47), \text { the } \\
\text { ratios }\left|I_{\text {neg }}\right| /\left|I_{\text {pos }}\right| \text {, } \\
\left|V_{\text {neg }}\right| /\left|V_{\text {pos }}\right| \text {, } \\
\left(\left|I_{\text {neg }}\right|+\left|I_{\text {zero }}\right|\right) /\left|I_{\text {pos }}\right| \text { or } \\
\left(\left|V_{\text {neg }}\right|+\left|V_{\text {zero }}\right|\right) /\left|V_{\text {pos }}\right|\end{array}$ & $\begin{array}{l}\text { - Use of the } I_{d} \text { parameter } \\
\text { - Under-voltage protection } \\
\text { - Under-/over-frequency } \\
\text { protection }(81 \mathrm{U} / 0) \\
\text { - Use of the } 3 I_{0} \text { and } 3 V_{0} \\
\text { components }\end{array}$ \\
\hline
\end{tabular}

Note: Overcurrent relays (50/51/51V) are suitable to protect the inverters if their output fault currents are not limited.

\begin{tabular}{|c|c|c|c|}
\hline \multicolumn{4}{|c|}{ Protection Zone 4 - Fault protection of branches containing DG sources } \\
\hline \multicolumn{2}{|c|}{ At the grid-connected operation mode } & \multicolumn{2}{|c|}{ At the islanded operation mode } \\
\hline Main protection & Back-up protection & Main protection & Back-up protection \\
\hline $\begin{array}{l}\text { - Under-/over-voltage relays } \\
(27 / 59) \\
\text { - Negative-sequence current and } \\
\text { voltage based protection } \\
\text { - Non-directional overcurrent } \\
\text { relays }(50 / 51,50 \mathrm{~N} / 51 \mathrm{~N} \text {, and } \\
51 \mathrm{~V}) \\
\text { - Directional overcurrent relays } \\
\text { (67) }\end{array}$ & $\begin{array}{l}\text { - THD detection of currents } \\
\text { and voltages } \\
\text { - Use of the ratios }\left|I_{\text {neg }}\right| /\left|I_{\text {pos }}\right| \text {, } \\
\left|V_{\text {neg }}\right| /\left|V_{\text {pos }}\right| \text {, } \\
\left(\left|I_{\text {neg }}\right|+\left|I_{\text {zero }}\right|\right) /\left|I_{\text {pos }}\right| \text { or } \\
\left(\left|V_{\text {neg }}\right|+\left|V_{\text {zero }}\right|\right) /\left|V_{\text {pos }}\right| \\
\text { - Protective relays using } 3 I_{0} \\
\text { and } 3 V_{0} \text { components }\end{array}$ & $\begin{array}{l}\text { - Under-/over-voltage relays } \\
(27 / 59) \\
\text { - Negative-sequence current } \\
\text { and voltage based } \\
\text { protection solutions } \\
\text { - THD detection of currents } \\
\text { and voltages } \\
\text { - Use of the ratios }\left|I_{\text {neg }}\right| /\left|I_{\text {pos }}\right| \text {, } \\
\left|V_{\text {neg }}\right| /\left|V_{\text {pos }}\right| \text {, } \\
\left(\left|I_{\text {neg }}\right|+\left|I_{\text {zero }}\right|\right) /\left|I_{\text {pos }}\right| \text { or } \\
\left(\left|V_{\text {neg }}\right|+\left|V_{\text {zero }}\right|\right) /\left|V_{\text {pos }}\right|\end{array}$ & $\begin{array}{l}\text { - Protective relays } \\
\text { using } 3 I_{o} \text { and } 3 V_{o} \\
\text { values } \\
\text { - Use of the } I_{d} \\
\text { parameter }\end{array}$ \\
\hline
\end{tabular}




\begin{tabular}{|c|c|}
\hline \multicolumn{2}{|l|}{ Protection Zone 5 - Fault protection of load branches } \\
\hline \multicolumn{2}{|l|}{ At both grid-connected and islanded operation modes } \\
\hline Main protection & Back-up protection \\
\hline $\begin{array}{l}\text { - Instantaneous and time-delayed overcurrent protection } \\
\text { modules (50/51 and } 50 \mathrm{~N} / 51 \mathrm{~N} \text { ) along with circuit breakers } \\
\text { - High-speed fuses } \\
\text { - Directional overcurrent protection relay (67) } \\
\text { - Under-voltage protection relay (27) } \\
\text { - Negative-sequence current and voltage based protection } \\
\text { relays (46 and } 47 \text { ) }\end{array}$ & $\begin{array}{l}\text { - THD detection of currents and voltages } \\
\text { - Use of the ratios }\left|I_{\text {neg }}\right| /\left|I_{\text {pos }}\right|,\left|V_{\text {neg }}\right| /\left|V_{\text {pos }}\right| \text {, } \\
\left(\left|I_{\text {neg }}\right|+\left|I_{\text {zero }}\right|\right) /\left|I_{\text {pos }}\right| \text { or }\left(\left|V_{\text {neg }}\right|+\left|V_{\text {zero }}\right|\right) /\left|V_{\text {pos }}\right| \\
\text { - Protective relays using } 3 I_{0} \text { and } 3 V_{0} \text { components: It is } \\
\text { proposed to distinguish about } 3 I_{0} \text { and } 3 V_{0} \text { values between } \\
\text { various fault situations and load unbalance cases in the } \\
\text { uni-grounded microgrid. }\end{array}$ \\
\hline
\end{tabular}

\section{Protection Zone 6 - Fault protection of common AC buses and trunk lines}

A trunk line in an AC microgrid is defined as a line to link two or more power sources and it does not include any load branches along its line length. In case of a multiple-microgrid system, a trunk line is understood as a line to link among individual MGs. A common AC bus is not a trunk line only if any load branches are connected to it, so fault protection systems of trunk lines and common buses will have some noticeable differences at this situation.

\section{At both grid-connected and islanded operation modes \\ Main protection solutions - Protection of AC trunk lines and common buses without any connection of load branches to them \\ - Differential protection: Differential current, differential energy, and differential impedance based protection solutions; \\ - Directional over-current relays (67): Directional overcurrent protection principles use both current and voltage parameters; or only current [6]; or only post-fault currents and no need of voltages and pre-fault currents [7]. \\ - Differential protection based on negative-sequence current components; \\ - Pilot relays are placed at terminals of trunk lines or common buses using various fault protection principles such as: (i) directional change of fault currents along with change in negative-sequence current and voltage values at pilot relays; (ii) directional change of fault currents along with change in THD values of phase currents and voltages at pilot relays; (iii) directional change of fault currents along with change in values of the ratios $\left|I_{\text {neg }}\right| /\left|I_{\text {pos }}\right|,\left(\left|I_{\text {neg }}\right|+\left|I_{\text {zero }}\right|\right) /\left|I_{\text {pos }}\right|,\left|V_{\text {neg }}\right| /\left|V_{\text {pos }}\right|$, or $\left(\left|V_{\text {neg }}\right|+\left|V_{\text {zero }}\right|\right) /\left|V_{\text {pos }}\right|$ at pilot relays; and (iv) Directional change of fault currents along with change in values of $I_{d}\left(I_{d}=\left|I_{a}\right|+\right.$ $\left.\left|I_{b}\right|+\left|I_{c}\right|\right), V_{a}, V_{b}$ and $V_{c}$ at pilot relays [8].}

- Admittance based protection principle;

Main protection solutions - Protection of AC common buses with load branches connected to them

In case of a load branch connected to an AC common bus, if any fault occurs at this common bus, it is impossible to detect directional change of currents before and after the fault. As a result, pilot relays which use different fault protection principles as mentioned in case of no load branches connected to the common bus, cannot be used to detect the faults. Similarly, use of differential relays is also ineffective. Only some following protection solutions are adaptable to solve the above problem, including:

- Directional over-current relays are effective to detect the faults when the common buses contain load branches.

- Admittance based protection relay can be used.

Back-up protection solutions

- ${ }^{2} t$ protection [9] - an overload temperature protection algorithm

- Using $3 I_{0}$ and $3 V_{0}$ components

Note: If primary protection relays fail to detect and isolate the faults, due to time-based or communication-based coordination strategies, downstream relays will operate one-by-one until the faults are cleared.

\section{Conclusion}

This paper has investigated transient responses of a uni-grounded LVAC microgrid through line-to-line, line-to-ground and three-phase fault tests, and a microgrid operation transition test. Transient simulation results are analysed and discussed through evaluating main parameters of a uni-grounded AC microgrid such as: phase currents and voltages, total harmonic distortion of currents and voltages, positive/negative/zero sequence current and voltage components, $3 I_{0}, 3 V_{0}$, voltages at a $d-q$ rotating reference frame. Based on the evaluations of the above parameters, possible fault protection methods are proposed for main and back-up protection of a uni-grounded MG. Thereby, technicians can properly select 
which main and back-up protection methods are optimal for their uni-grounded MGs. In future, the authors will study to shorten fault clearing time for microgrid protection solutions not based on phase currents and voltages through improvement of signal sampling techniques, harmonic and DC-offset filters.

\section{References}

[1] Lasseter, R. H. (2007). Certs microgrid. Proceedings of SoSE '07 IEEE International Conference on System of Systems Engineering (pp. 1-5).

[2] Vasquez, J. C., Guerrero, J. M., Miret, J., Castilla, M., \& Vicuña, L. G. (2010). Hierarchical control of intelligent microgrids. IEEE Ind. Electron. Mag., 4(4), 23-29.

[3] Guerrero, J. M., et al. (2013). Advanced control architectures for intelligent microgrids-Part I: Decentralized and hierarchical control. IEEE Trans. Ind. Electron., 60(4), 1254-1262.

[4] Guerrero, J. M., et al. (2013). Advanced control architectures for intelligent microgrids - Part II: Power quality, energy storage, and AC/DC microgrids. IEEE Trans. Ind. Electron., 60(4), 1263-1270.

[5] IEEE Application Guide for IEEE Std 1547 ${ }^{\mathrm{TM}}$ (2008). IEEE Standard for Interconnecting Distributed Resources with Electric Power Systems, IEEE Standard 1547.2-2008, pp. 1-217.

[6] Ukil, A., Deck, B., \& Shah, V. H. (2011). Current-only directional overcurrent relay. Sensors Journal, IEEE, 11(6), 1403-1404.

[7] Ukil, A., Deck, B., \& Shah, V. H. (2012). Current-only directional overcurrent protection for distribution automation: Challenges and solutions. Smart Grid, IEEE Transactions on, 3(4), 1687-1694.

[8] Duong, B. M., Lien, K. Y., Chen, S. L., Lu, Y. C., Chan, C. M., \& Chang, Y. R. (2015). Investigate dynamic and transient characteristics of microgrid operation and develop a fast-scalable-adaptable algorithm for fault protection system. Electric Power Systems Research, 120, 214-233.

[9] Nikkhajoei. H., \& Lasseter, R. H. (2007). Microgrid protection. Proceedings of Power Engineering Society General Meeting, IEEE (pp. 1-6).

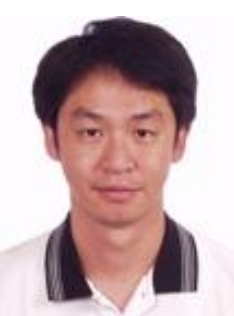

Keng-Yu Lien was born in 1969, Taiwan. He received his B.Sc. degree from National Tsing Hua University, Taiwan, and Ph.D. degree in electrical engineering from the same University, in 1991, 1998, respectively. In 1998, he joined the Industrial Technology Research Institute as a researcher of Electrical/Electromagnetic Measurement Laboratory. In 2003, he joined the Faculty of China University of Science and Technology, Taiwan, where he is currently an assistant professor. His current research interests include power system protection, micro-grid system protection and SOC development.

Duong Minh Bui was born in 1986, Vietnam. He received a bachelor degree in electrical engineering from CanTho University, Vietnam in 2008 and a master degree in electrical power engineering from University of Greenwich, United Kingdom in 2012. He is working towards a Ph.D. degree in electrical engineering at Chung Yuan Christian University, Taiwan, focusing on advanced protection and coordination systems for medium-voltage and low-voltage AC/DC microgrids. His research interests include energy management, power-flow control, and protection and coordination systems of microgrids.

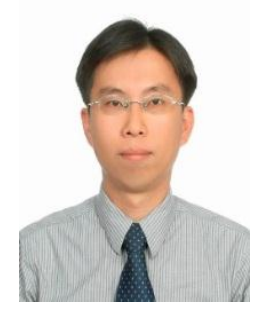

Yung-Ruei Chang received his $\mathrm{PhD}$ degree in electrical engineering from National Taiwan University in 2004. He is now the deputy director of Nuclear Instrumentation Division of the Institute of Nuclear Energy Research (INER), Atomic Energy Council, Taiwan, where he has been working since 1996 . Since 2005 , he has been responsible for power conditioning systems of the renewable energy project and leaded the distributed generation research group of INER. In 2007, he was a visiting scholar at the Future Energy Electronics Center of 
Virginia Polytechnic and State University, USA, where he joined to develop a high-efficiency DC-DC converter for solid oxide fuel cell. Now he is in charge of a microgrid project of INER. His research interests include microgrid technology, power electronic system, dependable computing, system reliability analysis and fault-tolerant system.

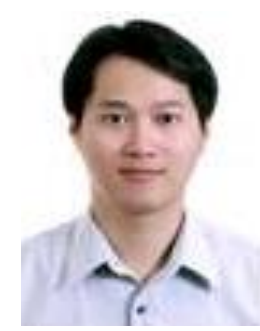

Yih-Der Lee received the B.S. and M.S. degrees in electrical engineering from National Taiwan University of Science and Technology (NTUST), Taipei, Taiwan, in 1997 and 1999, respectively. In 2009, he received the Ph.D. degree in electrical engineering from National Sun Yat-Sen University (NSYSU), Kaohsiung, Taiwan. From 1998 to 2010, he was an associate technical specialist at the Southern District Waste Management Plant, Environment Protection Bureau, Kaohsiung City Government. Since 2010, he joined the Institute of Nuclear Energy Research (INER), Atomic Energy Council, and currently is an associate researcher, which is responsible for developing smart grid technology. His research interests include renewable energy, microgrid, power electronics, power system control and stability. He is a member of the IEEE.

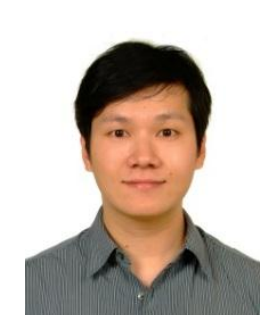

Jheng-Lun Jiang received the B.S. degrees in electrical engineering from National Kaohsiung University of Applied Sciences (KUAS), Kaohsiung, Taiwan, in 2007. He received his Ph.D. degree in electrical engineering from National Taiwan University of Science and Technology (NTUST), Taipei, Taiwan, in 2013. He is currently an associate developer with the Institute of Nuclear Energy Research (INER), Atomic Energy Council, Longtan, Taiwan. His research interests include renewable energy, microgrid, power system control and stability, and transient analysis.

Ching-Chih Lin was born on December 29, 1991, Taipei, Taiwan. He received the B.S. degree in electrical engineering from Chung Yuan Christian University (CYCU), Taoyuan, Taiwan, in 2014. Now he is an M.S. student in electrical engineering with CYCU, Taoyuan, Taiwan. 